\title{
Higher-level molecular phylogeny of the water mites (Acariformes: Prostigmata: Parasitengonina: Hydrachnidiae)
}

\author{
Miroslawa Dabert ${ }^{1}$, Heather Proctor $^{2}$, Jacek Dabert ${ }^{3 *}$
}

${ }^{1}$ Molecular Biology Techniques Laboratory, Faculty of Biology, Adam Mickiewicz University, Umultowska 89,61-614 Poznan, Poland,mirkad@amu.edu.pl

${ }^{2}$ Department of Biological Sciences, University of Alberta, Edmonton, Alberta, Canada T6G 2E9, hproctor@ualberta.ca

${ }^{3}$ Department of Animal Morphology, Institute of Environmental Biology, Adam Mickiewicz University, Umultowska 89, 61-614 Poznan, Poland, dabert@amu.edu.pl

*corresponding author

\begin{abstract}
With nearly 6000 named species, Hydrachnidiae (water mites) represent the largest group of arachnids that has invaded and extensively diversified in freshwater habitats. Water mites together with three other lineages (the terrestrial Erythraiae and Trombidiae, and aquatic Stygothrombiae), make up the hyporder Parasitengonina, which is characterized by having parasitic larvae and predatory nymphs and adults. Relationships between the Hydrachnidiae and other members of the Parasitengonina are unclear, as are relationships among the major lineages of water mites. Monophyly of water mites has been asserted, with the possible exception of the morphologically distinctive Hydrovolzioidea.

Here we infer the phylogeny of water mites using multiple molecular markers and including representatives of all superfamilies of Hydrachnidiae and of almost all other Parasitengonina. Our results support a monophyletic Parasitengonina including Trombidiae, Stygothrombiae, and Hydrachnidiae. A monophyletic Hydrachnidiae, including Hydrovolzioidea, is strongly supported. Terrestrial Parasitengonina do not form a monophyletic sister group to water mites. Stygothrombiae is close to water mites but is not nested within this clade. Water mites appear to be derived from ancestors close to Stygothrombiae or the erythraoid group Calyptostomatoidea; however, this relationship is not clear because of extremely short branches
\end{abstract}


in this part of the parasitengonine tree. We recovered with strong support all commonly accepted water mite superfamilies except for Hydryphantoidea, which is clearly paraphyletic. Our data support the previously proposed clades Protohydrachnidia (Hydrovolzioidea and Eylaoidea), Euhydrachnidia (all remaining superfamilies), and the euhydrachnid subclade Neohydrachnidia (Lebertioidea, Hydrachnoidea, Hygrobatoidea, and Arrenuroidea). We found that larval leg structure and locomotory behaviour are strongly congruent with the molecular phylogeny. Other morphological and behavioural characters, including host choice, are not as strongly correlated with phylogeny. Molecular dating suggests that the Hydrachnidiae arose about 235 MYA, and that Neohydrachnidia began to diversify about 155 MYA. Our results provide a strong framework for classification and for further elaboration at finer taxonomic scales, which will allow testing of ecological and behavioural hypotheses associated with the transition from terrestrial to aquatic life.

Keywords: Hydracarina; Prostigmata; molecular phylogeny; phylogenetic noise; molecular dating; character evolution

\section{Introduction}

Freshwater habitats have been repeatedly colonized by terrestrial invertebrates, including pulmonate snails and many different groups of insects (Thorp and Rogers, 2015). Among arachnids, spiders have only one truly subaquatic freshwater representative, but mites (Acari) have invaded fresh water many times (Proctor et al., 2015). Most mite taxa have not extensively diversified in this habitat, except for the originally marine Halacaroidea (about 60 described spp. in fresh water, Bartsch, 2008) and especially the Hydrachnidiae, "water mites" sensu stricto, also known as Hydrachnidia, Hydrachnellae, and Hydracarina. There are approximately 6000 described spp. of water mites in more than 400 genera (Di Sabatino et al., 2008 and Walter et al., 2009). Water mites occupy all possible standing and running freshwater habitats from phytotelmata (water bodies held by terrestrial plants) to groundwater to fast-flowing rivers; a few (members of the family Pontarachnidae) have invaded nearshore marine waters (Proctor et al., 2015). 
Water mites belong to the trombidiform hyporder Parasitengonina (Zhang et al., 2011, note that hyporder has traditionally been given the rank 'cohort', e.g. Krantz and Walter, 2009), members of which are characterised by a specific form of alternating calyptostasy (Kethley, 1991, for review see Belozerov, 2008), in which active instars (larva, deutonymph, adult) are interspersed with pupa-like non-feeding ones (protonymph, tritonymph). In Parasitengonina, larvae are generally parasitic, while deutonymphs and adults are free-living predators. Most larval water mites parasitize adults of aquatic insects, particularly chironomid flies (Smith and Oliver, 1986), and adults typically feed on cladoceran crustaceans and insect eggs and larvae (Proctor and Pritchard, 1989). Water mites are unusual among freshwater invertebrates in being colourful, with brilliant reds and oranges being most obvious, but they also display more subtle blues, greens and yellows (Proctor and Garga, 2004). They are also unusual among all mites in that some lineages have movable, internalized eye lenses sunk deep within the tissues of the prosoma rather than being set on the surface of the cuticle (Lang, 1905). Potential morphological synapomorphies of the Hydrachnidiae include the presence of two setae on the palpal genu of the larva (with the exception of the Stygothrombidiidae and Calyptostomatidae, other parasitengonines have only one seta), and postlarval instars with complex dermal structures (glandularia) in which a gland is paired with a seta that acts as a sensory trigger for releasing gland contents. The contents are assumed to have anti-predator functions (Kerfoot, 1982).

Current classification of the Parasitengonina (Walter et al., 2009) includes Hydrachnidiae together with three other lineages. Two of these, Erythraiae and Trombidiae, are composed of terrestrial taxa known generally as "velvet mites". Although not as morphologically or behaviourally diverse as water mites, the approximately 3000 species of terrestrial Parasitengonina (Varma, 1993, and Mąkol and Wohltmann, 2012) share their complex life cycle. The best known terrestrial parasitengonines have larvae that parasitize vertebrates ("chiggers" or "scrub itch mites", Trombiculidae and Leeuwenhoekiidae), and about 20 spp. of chiggers are known bite humans (Varma, 1993). The Erythraiae includes the superfamilies Calyptostomatoidea and Erythraeoidea, members of which can retract their stylet-like chelicerae or the entire gnathosoma including palps inside the anterior part of the body. The Trombidiae includes four superfamilies (Tanaupodoidea, Chyzerioidea, Trombiculoidea and Trombidioidea) that do not have any unique synapomorphies, although they do share the character state of having larvae with only a single seta on the palp genu. Members of the final lineage, Stygothrombiae, 
belong to the monotypic superfamily Stygothrombidioidea. These mites share an aquatic lifestyle with the Hydrachnidiae, but their phylogenetic relationship to the true water mites is unclear.

There has long been controversy about monophyly of water mites, with many workers up to the 1970's considering the Hydrachnidiae an artificial group of lineages that had independently invaded fresh water (see reviews in Barr, 1972 and Abé, 2000). More recently, the monophyly of most superfamilies of water mites has been asserted, with the possible exception of two taxa: Hydrovolzioidea and Stygothrombidioidea. The Hydrovolzioidea have been considered potentially unrelated to the rest of the water mites due to very different morphology of male internal genitalia (Barr, 1972) and apparent absence of ionic regulatory structures called genital acetabula (= genital papillae) (Alberti and Bader 1990). Kethley (1982) also considered the Hydrovolzioidea to represent a separate invasion of fresh water. Stygothrombidioidea, composed of the family Stygothrombidiidae with the sole genus Stygothrombium, is an enigmatic group of elongate, soft-bodied interstitial parasitengonines. They live in the substrate of cool streams and rivers in the Northern Hemisphere (Walter et al., 2009 and Proctor et al. 2015). Larvae are parasitic on stoneflies (Plecoptera), and nymphs and adults are likely predatory, though feeding activity has not been observed. Opinions vary as to whether stygothrombidiids belong within the Hydrachnidiae. Kethley (1982) states that they are "true water mites". Harvey (1998) and Jin (2000) also consider them water mites and place them as basal. In contrast, Walter et al. (2009) and Smith et al. (2010) classify them separately from the Hydrachnidiae.

Relationships of the Hydrachnidiae (with or without Stygothrombidioidea) to terrestrial members of the Parasitengonina are also unclear (Abé, 2000 and Zhang et al., 2011). Newell (1957) suggested that the semi-aquatic Johnstonianidae might be an evolutionary intermediate between fully terrestrial velvet mites and water mites. In a morphologically based cladistic analysis, Welbourn (1991) placed the water mites as sister to a clade of Tanaupodoidea (Chyzerioidea (Trombiculoidea + Trombidioidea)) based on two potentially synapomorphic states of larval leg setation. Based mainly on characters of the male reproductive system, Witte (1991a) placed the two terrestrial lineages Trombidioidea (= Trombidiae) and Erythraeoidea + Calyptostomatoidea (= Erythraiae) as sister to each other, with water mites sister to them; however this reconstruction did not include Stygothrombidioidea. Wohltmann (2000, Fig. 1) likewise considered the two terrestrial lineages to be sisters, but suggested that two families normally placed within Trombidioidea (Chyzeriidae and Tanaupodidae) might be more closely 
related to Hydrachnidiae. Very few of these trees appear to have been generated using explicit algorithms, and branch terminals are represented by generalized "groundplans" of higher-level taxa rather than by exemplar species (see Yeates, 1996). Most of these hypotheses were proposed based on key of water mites and other parasitengonines related to larval and adult morphology, host-parasite associations, and habitat preferences.

Here we present the first molecular phylogenetic analysis of water mites that includes representatives of all superfamilies of water mites and other Parasitengonina, including Stygothrombidioidea. We employ standard phylogenetic markers, DNA sequences coding for the small and large ribosomal subunit RNA genes (18S and 28S rDNA) and cytochrome $c$ oxidase subunit I (COI), to explore three main questions about the evolutionary history of water mites: (1) do the seven superfamilies considered part of the Hydrachnidiae in most current classifications (Hydrovolzioidea, Eylaoidea, Hydryphantoidea, Hydrachnoidea, Lebertioidea, Hygrobatoidea and Arrenuroidea, e.g. Walter et al., 2009) form a monophyletic group? (2) is Stygothrombiae a lineage within the Hydrachnidiae? (3) do the terrestrial parasitengones form a monophyletic sister clade to water mites? We also address several questions about relationships within the water mites. The most important concerns Witte's hypothesis (1991a) about the following large clades: Protohydrachnidia (Hydrovolzioidea + Eylaoidea), Euhydrachnidia (all other water mites) and Neohydrachnidia (Euhydrachnidia minus the Hydryphantoidea). We also explore the evolutionary history of key morphological and ecological characters by mapping their states onto our molecularly-derived phylogenetic trees, and present a fossil-calibrated chronological hypothesis for the origin of different lineages of the Hydrachnidiae.

\section{Material and Methods}

\subsection{Taxon sampling}

We analysed DNA sequences from 123 species of arachnids (Table 1), 64 of them representing all main water mite groups traditionally assigned to the superfamilial rank. We also included representatives of the Stygothrombidiodea ( 2 species) and all terrestrial parasitengonine superfamilies except Tanaupodoidea (19 species) as close outgroups. More distant outgroups were selected from among the main prostigmatan lineages ( 34 species). The whole mite tree was 
rooted by solifugids ( 4 species), which have been recently revealed as the likely sister group to acariform mites (Dabert et al., 2010, Pepato et al., 2010, Pepato and Klimov 2015). Detailed information about the sampled specimens is published with sequence data in GenBank under the listed accession numbers and can also be provided upon request. Mite exoskeletons after DNA extraction were mounted on slides and deposited as vouchers in the appropriate collections for material origins (Freshwater Invertebrate Collection, University of Alberta, Edmonton, Canada and Department of Animal Morphology, Adam Mickiewicz University in Poznan, Poland). DNA vouchers are deposited in the collection of the Molecular Biology Techniques Laboratory, Adam Mickiewicz University in Poznan, Poland.

\subsection{Molecular methods}

Total genomic DNA was extracted from individual mite specimens using DNeasy Blood and Tissue Kit (Qiagen GmbH, Hilden, Germany) as described by Dabert et al. (2008). When feasible, after DNA extraction the mite exoskeletons were preserved in 96\% ethyl alcohol or mounted on microscopic slides as primary vouchers. The COI gene fragment was amplified and sequenced with degenerate primers bcdF01 and bcdR04 (for primer details see Table S1 in supplementary material). The complete $18 \mathrm{~S}$ rDNA was PCR-amplified in two overlapping fragments of about 950 and 1500 bp each, using primer pairs $18 \mathrm{SF} \&$ rev960 and f390 \& rev18S, respectively. The following primer combinations were used initially to amplify $28 \mathrm{~S}$ rDNA sequences in two overlapping fragments each of about 2500 bp: 28SF0001 \& 28 SR2850 and 28 SF 1550 \& 28SR3980. If necessary, internal sequencing primers were used to amplify shorter 28S rDNA amplicons (Table S1).

PCRs were carried out in 109 reaction volumes containing 1x Type-it Microsatellite Kit (Qiagen), $0.59 \mathrm{M}$ each primer, and 49 of DNA template using a thermocycling profile of one cycle of $5 \mathrm{~min}$ at $96^{\circ} \mathrm{C}$ followed by 35 steps of $30 \mathrm{sec}$ at $95^{\circ} \mathrm{C}, 1 \mathrm{~min}$ at $50^{\circ} \mathrm{C}$, and $1 \mathrm{~min}$ for each $1 \mathrm{~kb}$ at $72{ }^{\circ} \mathrm{C}$, with a final step of 5 min at $72{ }^{\circ} \mathrm{C}$. Alternatively, amplifications were performed using HOT FIREPol Blend Master Mix (Solis Biodyne, Tartu, Estonia) or Q5 Hot Start High-Fidelity 2X Master Mix (New England Biolabs), following manufacturer's instructions. After amplification, samples were diluted with water (1:2) and 59 of the diluted 
PCR reaction was analyzed by electrophoresis on a $1 \%$ agarose gel. Samples containing visible bands were purified with thermosensitive Exonuclease I and FastAP Alkaline Phosphatase (Fermentas, Thermo Scientific) and sequenced with BigDye Terminator v3.1 on an ABI Prism 3130XL Analyzer (Applied Biosystems, Foster City, CA, USA). Sequence chromatograms were checked for accuracy using FinchTV 1.3.1 (Geospiza Inc.) and contigs were assembled in Geneious R6 (Biomatters Ltd.) and GenDoc 2.7.000 (Nicholas and Nicholas, 1997).

\subsection{Sequence alignments and initial sequence analyses}

The sequences were initially aligned by ClustalX 1.81 (Thompson et al., 1997) with default parameters (gap opening $=15$, gap extension $=6.66$, delay divergent sequences $=30 \%$, and DNA transition weight $=0.5$ ); if necessary, the obtained alignment was subsequently adjusted manually. Low-quality base calls that are typically found near the 5 ' and 3 ' ends and ambiguous hypervariable alignment positions in 28S rDNA were excluded from the dataset. Alignment gaps (indels) were treated as missing data. Character ambiguities due to gaps and/or poorly sequenced fragments in particular sequences were checked using Tree-Puzzle v.5.2 software (Schmidt et al., 2012). Sequences with $>50 \%$ ambiguous characters, if not sufficiently overlapping with other sequences, were discarded from the analyses. The final alignment has been published in TreeBASE under the study Accession No. xxx and can be provided upon request from the first author.

Choice of appropriate model of DNA sequence evolution for 18S and 28S rDNA was made using jModeltest 0.11 (Posada, 2008) for likelihood methods; the GTR + I + G model was appropriate for both markers. For COI DNA sequences the two-rate codon-based model was applied (Goldman and Yang, 1994) with invertebrate mtDNA genetic code.

\subsection{Phylogenetic analyses}

Tree reconstructions were performed using three methods: Maximum Parsimony (MP) and two likelihood approaches, Maximum Likelihood (ML) and Bayesian Inference with Markov Chain Monte Carlo (BI). MP and likelihood methods are assumed to exhibit differing sensitivity to computational artefacts, e.g. due to LBA and other phenomena (Anderson and Swofford, 2004, 
Mar et al., 2005; Merl et al., 2005, Kennedy et al., 2005 and Reeb et al., 2004). As has been shown for data concerning similar molecular markers and lineages (Dabert et al., 2010), the MP method is most prone to these systematic errors, although adding data may solve this problem in some degree (Pickett et al., 2006). Therefore the MP results should be treated as less reliable, but concordance of the results obtained by different methods can be interpreted as indicating the robustness of the phylogenetic reconstruction.

MP analyses were conducted by PAUP* 4.10 (Swofford, 2002) and performed on unordered characters using standard unweighted heuristic search strategy with tree-bisectionreconnection (TBR) branch swapping, with the starting tree obtained via stepwise addition with 1000 random-addition replicates. The secondary MP analyses were performed on reweighted characters according to rescaled consistency indices (RC). ML trees were searched using Garli v.2.0 (Zwickl, 2006) with 30 search replications. BI analyses of 4 independent chains were run on a parallel version of MrBayes 3. 2 (Ronquist et al., 2012) using the on-line Poznan Supercomputing-Network Center at Institute of Bioorganic Chemistry of the Polish Academy of Sciences, Poznan, Poland. Each run of the BI analyses was performed in $3-10 \times 10^{6}$ generations, and the trees were sampled every 1000 generation. The final consensus tree was generated from the burn-out fraction of initial trees after assessing the chain convergence in Tracer v.1.4 (Rambaut and Drummond, 2007) as judged by the average standard deviation of split frequencies dropping below 0.01. For concatenated alignment the partitioned ML and BI analyses were performed with appropriate substitution model for each partition.

Support for tree branches was calculated by the nonparametric bootstrap method (Felsenstein, 1985) with 500 replicates for MP analyses and 100 replicates for ML analyses. For the MP analysis, support for internal tree branches was additionally estimated by decay/support (D) indices (Bremer, 1988) calculated using PRAP v.2.0b3 software (Müller, 2004). For ML analysis, support for internal tree branches was additionally estimated by Shimodaira-Hasegawalike approximation of the likelihood-ratio test statistics (SHL) as implemented in RAxML v.7.2.8 (Stamatakis, 2006). The calculation of these support statistics is much faster than BS and generally more accurate for short branches (Pyron et al., 2011). We determined support for nodes in BI analysis from Bayesian posterior probabilities (PP) of each bipartition calculated for remaining trees representing the percentage of times each node was recovered by $50 \%$ majority rule consensus. Posterior probabilities below 0.95 are considered as recovered but unsupported, 
and $\geq 0.95$ as supported, which roughly correspond to $\geq 70 \%$ of bootstrap value (BS) (Douady et al., 2003) and to $\geq 85 \%$ of SHL support (Pyron et al., 2011). Comparison of obtained tree topologies was made by SH test using RELL 1000 bootstrap replications (Shimodaira and Hasegava, 1999), as implemented in PAUP *4.

We tested data for the presence of conflicting phylogenetic signals that may affect the results, e.g., due to long-branch attraction effects (reviewed by Kennedy et al., 2005). Consensus Network analysis (Bandelt, 1995 and Holland and Moulton, 2003) was conducted for detecting contradictory phylogenetic signals in reconstructed BMCMC trees as implemented in the software SplitsTree v.4.9.1 (Huson and Bryant, 2006). Contradictory signals in data, i.e., support for mutually exclusive branching, is shown as box-like parts of the graph, while areas of little conflict are represented by more tree-like parts. Visualization of the consensus networks was done by SplitsTree using 2500 trees chosen at random from the first run file of Bayesian analysis (burn-out trees); splits transformation was according to the convex hull method, no edge weights, threshold adjusted to show most common splits.

Comparison of DNA substitution rates between water mites and remaining trombidiform lineages and between particular water mite superfamilies, relative to the solifugid outgroup, was

performed through relative rate tests as implemented in RRTree (Robinson-Rechavi and Huchon, 1999). Taxa of uncertain position in a phylogenetic tree, called rogue taxa, may potentially affect the results of the phylogenetic analysis and pruning rogue taxa may improve the quality and support of the obtained reconstructions (Aberer et al., 2013). Exploring of this phenomenon was conducted by default algorithm of RogueNaRok software run from its web service (http://exelixis-lab.org/roguenarok.html).

Tree editing was performed using programs FigTree 1.4.2 (Rambaut, 2014), Mesquite, TreeView 1.66 (Page, 1996), and the tree-editing tool of MEGA 6 (Tamura et al. 2013).

\subsection{Divergence time estimation and character tracing}

Molecular dating for major water mite lineages was estimated by the Bayesian MCMC approach using BEAST 1.82 (Drummond et al., 2012). In age estimation analysis we used as constraints the ML tree of $18 \mathrm{~S}+28 \mathrm{~S}+\mathrm{COI}$ sequence data and 15 fossil calibration points available for different prostigmatan groups and the solifugid outgroup (Table 2). Substitution model 
parameters were set for partitions as in MrBayes reconstruction and uncorrelated lognormal relaxed clock (Drummond et al. 2006) and Yule speciation process (Gernhard, 2008) as tree prior was used. The exponential prior distribution of ages was set to fossil constraints. The divergence times are given as the mean and the 95\% highest posterior densities (HPDs) in millions of years with the 95\% HPDs intervals as the range of age estimation; median ages with 95\% HPDs credibility intervals were estimated by TreeAnnotator (a part of BEAST package).

Evolution of selected discrete morphological and ecological characters (arrangement of larval coxal plates, number of articulated leg I segments/pseudosegments in larva, eye lenses in postlarval stages, number of pairs of genital acetabula in adult, larval hosts, mode of searching for hosts, and habitat of postlarval stages, see Table S2) was traced onto the final phylogenetic tree by the software Mesquite 3.0 (Maddison and Maddison, 2014) using likelihood Markov kstate 1 parameter model for reconstruction of ancestral states in most characters. If the reversals were not fully justified biologically, also asymmetrical 2-parameter Markov model with differently set forward/backward rates of character state changes was applied.

\section{Results}

\subsection{Sequence analysis and phylogenetic trees}

The final 18S rDNA alignment comprised 2188 nucleotide positions (nps) for 116 taxa and contained 1120 variable sites (vs), of which 837 were parsimony informative (PI). The amount of missing data and wildcards exceed $50 \%$ for 3 haplotypes: those from two halacarids, Thalassarachna basteri (63.5\%) and Rhombognathides pascens (62.5\%), and one hydryphantid, Hydrodroma sp. 1 (74.5\%). The alignment of 28S rDNA contained $4385 \mathrm{nps}$ for 56 taxa and comprised 2569 vs and 1994 PI sites. For the 28S rDNA alignment the amount of missing data and wildcards exceed greatly 50\% in five cases: two camel spiders, Eusimonia wunderlichi (93.9\%) and Chanbria regalis (92.8\%), one eupodoid, Poecilophysis sp. (93.7\%), one trombidioid, Diplothrombium sp. (67.9\%), and one hydrachnid, Hydrachna sp. 1 (93.8\%). The tests (not shown) including and excluding those taxa containing high amounts of missing data and wildcards (mostly short sequences from GenBank) revealed that these taxa were always grouped with close relatives and never influenced tree topology; therefore these taxa were 
included in final analyses. The final alignment of the COI included 570 nps (395 vs, 361 PI sites) of unambiguous sequence data for 76 species. The COI sequences of the three Calyptostoma spp. contained the same one-amino acid deletion in the variable region of the alignment (at the position corresponding to asparagine 119 in the COI coded by NC_009984). Differences in substitution rate in the $18 \mathrm{~S}+28 \mathrm{~S}+\mathrm{COI}$ data set were observed in water mites and terrestrial Parasitengonina $(\mathrm{p}<0.05)$, but there were no significant differences between both groups and the remaining trombidiforms (for details see Fig. S1 in Supplementary Material).

All phylogenetic methods and dataset combinations (individual genes, $18 \mathrm{~S}+28 \mathrm{~S}, 18 \mathrm{~S}+$ $28 \mathrm{~S}+\mathrm{COI})$, except individual-gene MP and likelihood-based phylogenetic analyses of the COI sequences, produced trees that are largely congruent and stable in their main topology (Fig. 1, Figs. S2A-H, and Figs. S3-S9). The COI marker alone was unable to reconstruct reliable relationships not only between particular water mite lineages but also in other trombidiform taxa (data not shown); therefore COI-alone results will be not considered in further discussion. We use the well-resolved ML tree (topologically identical to the BI tree) from the concatenated multilocus dataset as the final tree for all subsequent discussion (Fig. 1).

\subsection{Monophyly of Hydrachnidiae and its position in Prostigmata}

Only two of the major prostigmatid lineages, Labidostommatides and Eleutherengonides, are supported as monophyletic (Fig. 1), a result found by all methods and dataset combinations (Figs. $\mathrm{S} 2 \mathrm{~A}-\mathrm{H}$ ). Labidostommatides was recovered as the most basal prostigmatid group with maximum support. Eupodides appears polyphyletic, as Eupodoidea, Bdelloidea, and Halacaroidea do not form a clade. Similarly, Anystides, traditionally including two cohorts, Anystina and Parasitengonina, is found to be polyphyletic. Three anystine superfamilies, Anystoidea, Caeculoidea, and Paratydeoidea, clustered with eleutherengonide Cheyletoidea, while the monophyletic Parasitengonina forms a clade with eupodide Halacaroidea. The sister relationship of Halacaroidea with Parasitengonina is recovered with strong support. The monophyletic Stygothrombiae branches off outside the Hydrachnidiae, and this exclusion of Stygothrombiae from within water mites was recovered by all analyses.

Water mites s.s. (Hydrachnidiae without Stygothrombiae) are recovered with strong support as a highly derived monophyletic group in Prostigmata (Fig.1, Figs. S2A-H). The sister 
group of water mites was not unequivocally recovered. Sister relationship between Stygothrombiae and Hydrachnidiae is recovered in the final tree, but in other analyses this clade is supported only in the $28 \mathrm{~S} \mathrm{BI}$ analysis (Fig. S2D). The alternative hypothesis that terrestrial parasitengonine mites constitute a clade being a sister group of water mites was unequivocally rejected by the SH test $(\mathrm{p}<0.05)$. The remaining analyses point to the taxa Erythraeoidea, Calyptostomatoidea and Stygothrombidioidea as candidates for the closest relative to Hydrachnidiae; only the 18S MP tree recovered the semi-aquatic trombidioid Johnstonianidae as a water mites' closest relative, but without statistical support ( $\mathrm{SH} \mathrm{p}<0.05$, Fig. S2A). The hypothesis that the whole grouping Erythraeoidea + Calyptostomatoidea + Stygothrombioidea is a sister group of water mites is supported only in the 28S MP tree (Fig. S2C), but this clade is not present in any of the other reconstructions. Most often the Calyptostomatoidea is recovered as a sister taxon of water mites s.s. This relationship was recovered by $18 \mathrm{~S}$ ML and BI analyses (Fig. S2B), by both MP and likelihood analyses for $18 \mathrm{~S}+28 \mathrm{~S}$ dataset (Fig. S2F), and by MP analysis of the $18 \mathrm{~S}+28 \mathrm{~S}+\mathrm{COI}$ dataset (Fig. S2G). Calyptostomatoidea was also recovered as a sister group of water mites when the codon-based model of DNA sequence evolution was replaced by a model estimated independently for each of the three codon positions for the COI partition in $18 \mathrm{~S}$ $+28 \mathrm{~S}+\mathrm{COI}$ dataset (data not shown). The SH test also shows that none of the competing hypotheses concerning sister-group relationship in water mites is significantly better than any other one $(\mathrm{p}>0.05)$.

\subsection{Internal phylogenetic structure of the Hydrachnidiae}

The internal structure of water mites revealed two main groups: Hydrovolzioidea and Eylaoidea (= the Protohydrachnidia of Witte, 1991a) with strong support, and the remaining water mites (Euhydrachnidia) with maximum support (Fig. 1). This relationship was consistently recovered as supported by most methods and markers (Figs. S5-S9) and SH test $(p<0.05)$. Representatives of the five remaining water mite superfamilies were recovered as a clade with maximum support. This group consists of several clades including those corresponding to four of traditionally defined superfamilies: Hydrachnoidea, Hygrobatoidea, Arrenuroidea, and Lebertioidea. Lebertioidea is set basally as a sister group to a clade grouping Hydrachnoidea, Hygrobatoidea and Arrenuroidea. This relationship is found by all datasets in likelihood analyses. 
Hydrachnoidea and Hygrobatoidea are recovered in sister relationship as the most derived water mites (Fig. 1). However, in other analyses Hydrachnoidea was also discovered as a sister group to the remaining Euhydrachnidia (Figs. S5, S7) or in an unresolved relationship with Hygrobatoidea and Arrenuroidea (Figs. S3, S6, S8), but these hypotheses were rejected by the SH test $(\mathrm{p}<0.05)$.

The fifth named euhydrachnid superfamily Hydryphantoidea was never recovered as a clade, irrespective of the method and dataset combination. In Hydryphantoidea, only the basal family Hydrodromidae is monophyletic (Fig. 1), while the remaining species, classified as belonging to Hydryphantidae, are arranged in a stair-like paraphyletic group of taxa set basally to the superfamilies Lebertioidea, Arrenuroidea, Hydrachnoidea, and Hygrobatoidea (= the Neohydrachnidia of Witte, 1991a).

At the finer systematic level, the family Limnesiidae (Fig. 1) was recovered with strong support as a member of Lebertioidea, not Hygrobatoidea. In the same analysis, Sperchontidae was found as a member of Lebertioidea with strong support. All remaining clades corresponding to family level as suggested by recent classifications were reconstructed congruently across all analyses. Finally, the unionicolid genus Neumania was recovered as a polyphyletic group, with N. distincta basal for the family and the other Neumania sp. as sister to Unionicola spp.

\subsection{Phylogenetic noise and rogue taxa}

In spite of moderate branch support for some clades there is no evidence for strong contradictory phylogenetic signals in the parasitengonine data (Fig. 2). At the threshold of alternative hypotheses set to $33 \%$ there are two sources of conflict in the water mite subtree in the $18 \mathrm{~S}$ reconstructions. The sister relationship Hydrachnoidea-Hygrobatoidea is preferred over Hydrachnoidea-Arrenuroidea (57.3:33.4). The second conflict concerns the monophyly of Arrenuroidea, which is only slightly more often recovered as a clade (33.4) than as a paraphyletic group with Mideopsis joining basally to Hydrachnoidea (30.2). In the $18 \mathrm{~S}$ tree there is also another conflict concerning terrestrial Parasitengonina with almost equivocal options regarding the basal group to the clade Calyptostomatoidea + water mites: the basal group could be either Stygothrombioidea (38.4) or Trombidioidea (42.1). 
The $28 \mathrm{~S}$ tree has even less conflict than the $18 \mathrm{~S}$. There is only one pair of alternatives at the same threshold limit, which concern the sister-group relationships of the most distal superfamilies of water mites. This time the hypothesis that Hydrachnoidea is the closest relative to Arrenuroidea is preferred over an Arrenuroidea-Hygrobatoidea clade (55.6 and 43.9, respectively).

Phylogenetic reconstruction conducted on concatenated multilocus data shows no conflict at the $33 \%$ threshold limit. Lowering the threshold to $25 \%$ revealed conflicts only inside the paraphyletic Hydryphantoidea.

Searching for and eliminating rogue taxa did not improve results. The hygrobatoid Feltria, lebertioid Frontipoda and erythraeoid Balaustium were selected as potentially having the most detrimental influence on the consensus tree. However, values of the RogueNaRok coefficient were low $(0.139,0.088$, and 0.124 , respectively) and pruning of these taxa from the analysis did not change tree topology or branch supports. Therefore we present the results with the entire set of taxa.

\subsection{Age estimation}

Based on the BEAST analysis, the common ancestor of the Parasitengonina separated from the ancestor of halacarids in the lower Pennsylvanian Carboniferous, about 320 (270-345) MYA (Fig. 3). The split of the common ancestor of Stygothrombiae and water mites occurred in the Ladinian Triassic, about 235 (200-275) MYA. The two main water mites lineages, clade Hydrovolzioidea-Eylaoidea (Protohdrachnidia) and the clade unifying all remaining superfamilies (Euhydrachnidia), emerged about 6 million years after the origin of water mites. The time of crown origin (radiation) of the Euhydrachnidia is estimated in the lower Jurassic, about 180 (160-215) MYA. Finally the origin of Neohydrachnidia (Arrenuroidea, Hydrachnoidea, Hygrobatoidea, and Lebertioidea) is estimated at the Kimmeridgian in the Upper Jurassic, about 155 (140-170) MYA.

\subsection{Character tracing}


Key characteristics of water mites and other parasitengonines related to host-parasite associations, larval and adult morphology, and habitat preferences were traced on the final tree (Table S2, Fig. 4A-G). The insect host taxa chosen by parasitic larvae are poor predictors of the phylogenetic structure of Parasitengonina (Fig. 4A). The most prevalent and probably ancestral hosts are Diptera. Other insect orders were hosts of limited number of various parasitengonine mite clades that are usually distantly related.

Morphological features, especially of larvae, much better define large subtrees of Parasitengonina. Plates of coxae II and III (Fig. 4B) are separated from each other in larvae in all terrestrial parasitengonines, Stygothrombium, and basal water mites (Hydrovolzioidea, Eylaoidea, Hydryphantoidea, partly Lebertioidea). They are adjoining or fully fused in most Lebertioidea, all Arrenuroidea, and Hygrobatoidea. The free plates in Hydrachnoidea are probably not a reversal but retaining of plesiomorph character state as shown by character states probabilities in ancestral nodes leading to this water mite superfamily. That implies also three independent partial and complete fusions of plates in remaining water mite clades. Reduction in number of articulated segments in larvae from six to five (Fig. 4C) arose independently in distal Trombidioidea, neohydrachnid water mites and in Stygothrombidioidea. Adult morphology is less phylogenetically informative. Eye lenses (Fig. 4D) lying externally on the integument surface appear plesiomorphic to lenses submerged below body surface. Internal lenses are most typical for Stygothrombidioidea and derived water mite taxa but are reconstructed as having appeared independently in the clade Hygrobatoidea-Arrenuroidea and also in some Lebertioidea; the external lenses in Hydrachnoidea and Torrenticolidae are reversals. The number of pairs of genital acetabula in adults, considered as an important key feature for differentiating groups of terrestrial Parasitengonina, is poorly structured phylogenetically (Fig. 4E). In only one case does the number of genital acetabula clearly define a clade: the total loss of genital acetabula is a synapomorphy of Erythraeoidea. Multiplication of acetabula above three pairs has occurred independently in various hydracarine taxa, including within a single genus (Unionicola).

Tracing of mode of host searching and habitat preferences indicate a high congruence between evolution of these characteristics and phylogenetic reconstruction of parasitengonine mites. The derived behaviour of searching for insect hosts below the water's surface is typical for neohydrachnid water mites. It appeared also independently in the hydryphantid Wandesia and Stygothrombidioidea (Fig. 4F). A subaquatic lifestyle in postlarval stages (Fig. 4G) is a 
synapomorphy of the clade Stygothrombidioidea-Hydrachnidiae (reversal to semiaquatic habitats in Tyrrellia).

\section{Discussion}

\subsection{Monophyly of Hydrachnidiae and its position in Prostigmata}

Our data support a monophyletic Parasitengonina with subcohorts Trombidiae, Stygothrombiae, and Hydrachnidiae as defined by Walter et al. (2009). The subcohort Erythraiae is revealed as an artificial paraphyletic taxon due to Calyptostomatoidea being set in a clade with Stygothrombidioidea and Hydrachnidiae. Hypotheses about relationships among Parasitengonina are often grounded using the hyporder Anystina, specifically the Anystidae (whirligig mites), as the outgroup. Welbourn (1991), Witte (1991a), and Witte and Döring (1999) use Anystidae as the outgroup for morphological character-state polarization. Also Söller et al. (2001) used sequence data from an Anystis species to root the tree in their molecular analysis of terrestrial parasitengonine relationships with one water mite, Todothyas (previously Thyas) barbigera. However, our phylogenetic analyses recovered with high support the eupodide Halacaroidea, instead of Anystina, as the sister group of Parasitengonina. A close relationship between halacaroids and parasitengonines was suggested by Witte (1991b) and recently supported by Pepato and Klimov (2015).

Our results indicate that terrestrial Parasitengonina do not form a monophyletic group sister to water mites, and the water mites are not the most basal group within the Parasitengonina. Although monophyly of water mites is currently widely accepted by acarologists, this is the first confirmation based on molecular rather than morphological characters. In particular, Barr (1972), Smith and Oliver (1986), and Schwoerbel (1986) postulated that the Hydrovolzioidea was not directly related to the remaining Hydrachnidia, implying a polyphyletic origin of water mites. Results of our analyses unambiguously indicate that a monophyletic Hydrachnidiae is strongly supported clade and that Hydrovolzioidea is undoubtedly a member of this clade.

Our data show that the Stygothrombidioidea (= Stygothrombiae) is close to water mites but is not nested within this clade. In acarological works concerning water mites the superfamily is variable omitted, treated as a putative water mite taxon, or described as 'enigmatic'. The 
superfamily was transferred from Trombidioidea to water mites by Harvey (1998) but was not recognized as a member of Hydrachnidia by Walter et al. (2009), in which Hydrachnidiae and Stygothrombiae are treated as separate taxa at the same rank. Harvey (1998) concluded that Stygothrombioidea should be placed as a sister group to the remaining water mites. The position of Stygothrombioidea in our phylogenetic trees is ambiguous. Although the final multilocus reconstruction based on likelihood methods recovered this taxon as a basal to the water mite subtree, this placement is inconsistent and poorly supported. The alternative hypotheses obtained from our phylogenetic analyses, especially those suggesting Calyptostomatoidea as a basal taxon, are not significantly worse.

The next key question concerning water mite evolutionary history, partly resulting from the previous problem with Stygothrombioidea, is the relationship between Hydrachnidiae and the remaining parasitengonine taxa. There are two mutually exclusive scenarios: water mites are derived from terrestrial parasitengonine stock (Welbourn, 1991, Witte, 1991a, Witte and Döring, 1991, Witte and Olomski, 1999, Pepato and Klimov, 2015) or water mites are basal (or perhaps sister) to terrestrial parasitengonines (Söller et al., 2001 and Wohltmann, 2000). Our analyses unequivocally prefer the first hypothesis: water mites evolved from terrestrial ancestors, and are probably the most derived group of Parasitengonina. As it was already presented above, the sister-group of water mites is not clear. Most probably it is one of the two superfamilies, either Stygothrombidioidea or Calyptostomatoidea. It is less probable that water mites have a common ancestor with a clade grouping Calyptostomatoidea, Stygothrombioidea, and Erythraeoidea. Our data's inability to answer this question is probably due to extremely short branches in this part of part of the Parasitengonina tree. Since no conflicting data and rogue taxa were found around these branching points we suggest that more extensive sampling could produce greater resolution. Only the 18S MP tree presented the semi-aquatic trombidioid family Johnstonianidae as water mites' closest relative as suggested by Newell (1957), however, without statistical support. Our data rather support Johnstonianidae as a sister group of remaining trombidiods. Also, we do not confirm the results of Pepato and Klimov (2015) postulating Erythraeoidea alone as a sister group of water mites; this relationship was never recovered by any of our analyses.

\subsection{Phylogenetic relationships within Hydrachnidiae}


All superfamilies that are widely accepted in most current taxonomies (see Table 1), except Hydryphantoidea, form well supported clades in our analyses. We confirm the doubts concerning the monophyly of both Hydryphantoidea and Hydryphantidae (Harvey, 1998); we reconstructed both taxa as paraphyletic. As the most basal hydryphantoid taxon we reconstruct the family Hydrodromidae; however, as we did not sample members of several other hydryphanotid families (e.g., Ctenothyadidae, Teratothyadidae), this basal position is only tentative. Our data do not support Harvey's (1998) view that Sperchontidae warrants a separate superfamily that is not related to the remaining lebertioids. In our tree Sperchontidae is nested within the Lebertioidea as a sister group of Teutoniidae.

We do not confirm suggestions of Witte (1991) and Witte and Döring (1999) that the superfamily Hygrobatoidea might be paraphyletic. The family Limnesiidae is the most problematic taxon that sometimes is included in Hygrobatoidea (Cook, 1974, Walter et al., 2009 and Zhang et al., 2011), and sometimes in Lebertioidea (Harvey, 1998). In our tree this family is undoubtedly placed within Lebertioidea, probably as the sister group of the clade Oxidae (Lebertiidae, Torrenticolidae).

Phylogenetic hypotheses concerning the internal relationships among water mite lineages are scarce and based on morphological and to a lesser extent behavioural data. The most comprehensive cladistic reconstruction of phylogenetic relationships of water mites was presented by Witte (1991a) and Witte and Olomski (1999). In general, their reconstruction is consistent with our results. We fully support the concept of dividing water mites into the "old" Protohydrachnidia (Hydrovolzioidea + Eylaoidea) and the "new" Euhydrachnidia (grouping the remaining superfamilies). Moreover, we also reconstructed their "modern" Neohydrachnidia within the Euhydrachnidia and including the Lebertioidea, Hydrachnoidea, Hygrobatoidea, and Arrenuroidea. We did not recover the "Achihydrachnidia" clade proposed by Jin (2000) to consist of Hydrachnoidea, Hydryphantoidea and Eylaoidea.

However, in our analysis the internal structure of neohydrachnids differs from that previously proposed. The Hydrachnoidea are red, large-bodied mites with external eye lenses and are superficially similar to the Eylaoidea and some Hydryphantoidea. Hydrachnoidea is typically presented together with these superfamilies towards the beginning of water mite taxon lists, implying a relatively basal place in the phylogeny (e.g., Cook, 1974). In contrast, hydrachnoids have some 'modern' features such as 5 -segmented legs in larvae and subaquatic searching for 
host insects (see discussion below). In the morphological reconstruction of Witte (1991a) and Witte and Olomski (1999), Hydrachnoidea is basal to the clade (Sperchontoidea,(Lebertioidea(Hygrobatoidea, Arrenuroidea))) and Hygrobatoidea are paraphyletic. Our data consistently show Lebertioidea as most basal, with Sperchontidae nested within this clade, to the more diverged clade (Arrenuroidea,(Hydrachnoidea, monophyletic Hygrobatoidea).

Our reconstruction differs to a great extent from the hypotheses proposed by Harvey (1998). His reconstruction suggests a "stair-like" tree topology with all superfamilies shown as clades. In Harvey's tree the basal Hydrovolzioidea are closely related to the Eylaoidea, as reconstructed by our and Witte's analyses, but these two taxa are separated by Hydryphantoidea. Similarly to Witte's morphological reconstruction, Harvey presents Hydrachnoidea as basal to the remaining water mite superfamilies. Although the phylogenetic position of Hydrachnoidea was unstable in our analyses, none of likelihood analyses supported Hydrachnoidea as basal to other Euhydrachnidia.

The distal part of the water mite tree is rather ambiguously reconstructed by all analyses carried out so far, including ours. This ambiguity is probably caused by very short branches connecting neohydrachnid superfamilies. Wiens et al. (2008) found short branches to be very difficult to resolve with high confidence even if large multilocus datasets are applied. The very short basal branches suggest that there was a rapid radiation of the neohydrachnid superfamilies and a subsequent accelerated speciation rate in new niches.

\subsection{Evolution of key features of water mites and the age of lineages}

Compared to adults, larval water mites show a more conservative morphology that is more readily homologized among taxa and has proven useful for systematics and phylogenetic reconstruction (e.g., Smith, 1976, 1982, and Zawal, 2008). We found that larval leg structure (coxal morphology, segment number) was strongly congruent with the molecular phylogeny (Fig. 4B, C, F). Fusion of coxae, reduction in segment number, and switch from searching for hosts above the water's surface by walking and jumping to below it by swimming are also correlated. Our data show that the reduction to five segments and subaquatic searching have independently arisen in the Stygothombidioidea. It seems likely that the reduced number of leg segments and 
fusion of coxae improves swimming efficiency in the larvae; however, Wandesia (Hydryphantoidea) independently evolved subaquatic searching without showing any such changes in leg structure.

True flies (Diptera) are the most common host among all parasitengonine lineages. Although basal lineages within the Hydrachnidiae have a greater diversity of hosts, many still include true flies among them, resulting in Diptera being selected as the most likely host for the ancestor of all water mites (Fig. 4A). The beginning of the diversification of water mites reconstructed by BEAST analysis (ca. 235 MYA, Fig. 3) is compatible with the timing of the origin of Diptera estimated at about 242 MYA (Yeates et al., 2007 and Bertone et al., 2008). This suggests that dipteran hosts of terrestrial parasitengonines are most probably a secondary host group given that our analysis indicates that the terrestrial Parasitengonina originated about 80 million years before the presumed origin of Diptera.

Internalization of eye-lenses in aquatic parasitengonines potentially happened three times, in the Stygothrombidioidea and twice in the Neohydrachnidia. Reconstruction is ambiguous in the latter group, due to Hydrachna possessing external lenses (potentially a reversal), and variation in the character within the Lebertioidea. The function of internalized eyes and the ability to move them (at least in the Hygrobatoidea, H.C. Proctor, pers. obs.) is unclear. The eyes are unlikely to be image-forming (Lang, 1905) but they may be able to detect light intensity and wavelengths, perhaps providing some indication to the mites about time of day and water depth (as wavelengths of light will be differentially attenuated with depth). Some taxa of water mites are strongly attracted to light traps placed out at night (Proctor et al., 2015).

Three pairs of genital papillae (= acetabula) in adults is plesiomorphic for the Acariformes (Krantz, 2009), and from this character state all combinations appear to have evolved independently in various distantly related mite groups. Multiplication of genital acetabula from the ancestral number of three pairs has happened repeatedly in water mites. Little phylogenetic pattern is revealed, and variation in number is high within certain families and genera. Acetabula are involved in osmotic regulation, and it seems likely that adaptation to waters of differing conductivity has selected for diversity in size and number of these structures (Alberti and Bader, 1990).

The fossil record for water mites is unhelpful with regard to origins of the group, as it is limited to recent specimens in Tertiary amber (Cook, 1957 and Poinar, 1985); however, 
geographical distribution of all superfamilies except Hydrovolzioidea (principally Laurasian) in all major landmasses except Antarctica suggests that water mites arose in the Paleozoic and had diversified into the extant superfamilies by the Triassic (Walter et al., 2009, p. 257).

Results of our molecular dating analysis indicate that the Hydrachnidiae arose in Triassic (235 MYA), and that the Neohydrachnidia began to diversify about 155 MYA. The estimate of the origin of Neohydrachnidia seems inconsistent with the current geographical distribution of Arrenuroidea, Hydrachnoidea, Hygrobatoidea, and Lebertioidea which suggests that the ancestors of these superfamilies were present during Pangaean times (about 300 - 175 MYA) when all continents formed a single land mass (Frisch et al., 2011). One source of the inconsistency of molecular dating of water mites with the implications of their biogeography might be the heterogeneity in substitution rate that was observed across parasitengonine lineages and DNA markers (Fig. S1). This heterogeneity may mislead molecular dating (Philips, 2009), e.g., by smoothing the chronograms in a way that results in divergences occurring at evenly spread time intervals (Britton, 2007). The second source of uncertainty that could influence molecular dating analyses might result from biased sampling of calibration points. Among 15 calibrated nodes there is only one for Hydrachnidiae and it is represented by a relatively young amber fossil of an arrenuroid mite (12 MYA). The second known fossil of a water mite has been ambiguously classified as belonging to either the Hygrobatoidea, Arrenuroidea or Lebertiodea (Poinar, 1985) and therefore could not be used as calibration point for a defined clade.

\section{Conclusions}

Among previous phylogenetic hypotheses for water mites, our results are the most consistent with the cladistic reconstruction of relationships presented by Witte (1991a) and Witte and Olomski (1999). A monophyletic Hydrachnidiae is strongly supported by our data as well as the major groupings Protohydrachnidia (Hydrovolzioidea + Eylaoidea) and Euhydrachnidia (including the five remaining superfamilies). Hypotheses about the paraphyly of Hydryphantoidea and the Neohydrachnidia clade of Lebertioidea, Hydrachnoidea, Hygrobatoidea, and Arrenuroidea are also well supported by our data.

Morphological and ecological characters used for phylogenetic reconstruction in water mites, even they are well correlated with the molecular phylogeny, in most cases characterize 
very broad groups, so their overall usefulness for reconstruction of phylogenetic relationships among water mites is limited.

Most probably water mites originated on Pangaea and their radiation was correlated with the origin of Diptera. Our molecular dating analysis suggest that Neohydrachnidia originated and diversified after Pangaea separated into different continents. This is in disagreement with the current knowledge about the distribution of living water mites' superfamilies. This result might be an artifact due to the existence of only one suitable and a relatively young fossil for water mites. Discovering more ancient fossil records that could be used as calibration points for water mites is crucial to resolve this problem.

In our analyses, the sister group to water mites was either Stygothrombidioidea or Calyptostomatoidea. This should be tested by additional morphological and molecular study. Both Stygothrombidioidea and Calyptostomatoidea are monogeneric taxa with relatively few species each, therefore molecular analysis is unlikely to be improved by more sampling within

these taxa but rather by using more sequence data and by additional sampling of higher taxa of terrestrial parasitengonines missing from our study, e.g. Tanaupodoidea.

Our results provide a strong framework for classification of water mites and for further elaboration of their relationships at finer taxonomic scales. In our study we sampled only 20 of the 57 named water mite families and 33 of the about 400 genera (di Sabatino et al. 2008). It is only with greater inter- and intrafamilial resolution that we will be able to rigorously test hypotheses about the transition from terrestrial to aquatic life, evolution of host-spectra, internalization of eyes, aposematism (Proctor and Garga, 2004), sperm-transfer (Proctor, 1991) and other aspects of morphology, ecology and behaviour of this diverse and fascinating group of animals.

\section{Acknowledgements}

We are deeply grateful to Hans Klompen (Department of Evolution, Ecology and Organismal Biology, Ohio State University, USA) for providing mites and sequence data for this study and for useful comments on the draft version of the MS. We also thank Reinhard Gerecke (Tübingen, Germany), Joanna Mąkol (Dep. of Zoology and Ecology, Agricultural University of Wroclaw, Poland), Peter Martin, (Zoological Institute: Limnology, Kiel University, Germany), Rodger Mitchell (Ohio State University, Columbus, OH; deceased), Harry Smit (Zoological Museum, 
Amsterdam, The Netherlands), Cal Welbourn, (Florida Department of Agriculture and Consumer Services, Gainesville, FL), Mariusz Więcek (Dept. of Animal Morphology, AMU) and Andreas Wohltmann (Ritterhude, Germany) for providing an important part of the mite material used in this study. SEM images of mites in the graphical abstract were kindly provided as follows:

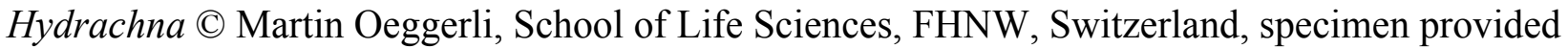
by Heather Proctor; Stygothrombium by Heather Proctor; Calyptostoma by Dave Walter, University of the Sunshine Coast, Maroochydore, Australia. The funding for this work came from the Polish MSHE grant \# N303 017937 (MD) and National Science Centre \#2014/13/B/NZ8/04679 (JD), and a Natural Sciences and Engineering Research Council of Canada (NSERC) Discovery Grant (HP).

\section{References}

Abé, H., 2000. Water mites: phylogeny and evolution. Journal of the Acarological Society of Japan 9: 1-13.

Aberer, A.J., Krompass, D., Stamatakis, A., 2013. Pruning rogue taxa improves phylogenetic accuracy: an efficient algorithm and webservice. Syst. Biol. 62, 162-166.

Alberti, G., Bader C., 1990. Fine structure of external 'genital' papillae in the freshwater mite Hydrovolzia placophora (Hydrovolziidae, Actinedida, Actinotrichida, Acari). Exp. Appl. Acarol. 8, 115-124.

Anderson, F.E., Swofford, D.L., 2004. Should we be worried about long-branch attraction in real data sets? Investigations using metazoan 18S rDNA. Mol. Phylogenet. Evol. 33, 440-451.

Bandelt, H.-J., 1995. Combination of data in phylogenetic analysis. Plant Syst. Evol. Suppl. 9, 355-361.

Barr, D., 1972. The ejaculatory complex of water mites (Acari: Parasitengona): morphology and potential value for systematics. Life sciences contributions/Royal Ontario Museum 81, 187. 
Bartsch, I., 2008. Global diversity of halacarid mites (Halacaridae: Acari: Arachnida) in freshwater. Hydrobiologia 595, 317-322.

Belozerov, V.N., 2008. Calyptostasy: its role in the development and life histories of the parasitengone mites (Acari: Prostigmata: Parasitengona). Acarina 16, 3-19.

Bertone, M.A., Courtney, G.W., Wiegmann, B.M., 2008. Phylogenetics and temporal diversification of the earliest true flies (Insecta: Diptera) based on multiple nuclear genes. Syst. Entomol. 33, 668-687.

Bremer, K., 1988. The limits of amino acid sequence data in angiosperm phylogenetic reconstruction. Evolution 42, 795-803.

Britton, T., Anderson, C.L., Jacquet, D., Lundqvist, S., Bremer K., 2007. Estimating divergence times in large phylogenetic trees. Syst. Biol. 56, 741-752.

Cockerell, T.D.A., 1917. Arthropods in Burmese amber. Am. J. Sci. 44, 360-368.

Coineau, Y., Magowski, W.L, 1994. Caeculidae in amber. Acarologia 35, 243-246.

Cook, D.R., 1957. Order Acarina. Suborder Hydracarina. Genus Protoarrenurus Cook, n. gen., in: Palmer, A.R. (Ed.) Miocene arthropods from the Mojave Desert, California. Professional Papers, Geological Survey No. 294-G, pp. 248-249.

Cook, D.R., 1974. Water Mite Genera and Subgenera. Memoirs of the American Entomological Institute. 21, 1-860.

Dabert, J., Ehrnsberger, R., Dabert, M., 2008. Glaucalges tytonis sp. n. (Analgoidea, Xolalgidae) from the barn owl Tyto alba (Strigiformes, Tytonidae): compiling morphology with DNA barcode data for taxon descriptions in mites (Acari). Zootaxa 1719, 41-52.

Dabert, M., Witalinski, W., Kazmierski, A., Olszanowski, Z., Dabert, J., 2010. Molecular phylogeny of acariform mites (Acari, Arachnida): Strong conflict between phylogenetic signal and long-branch attraction artifacts. Mol. Phylogenet. Evol. 56, 222-241.

Di Sabatino, A., Smit, H., Gerecke, R., Goldschmidt T., Matsumoto, N., Cicolani, B., 2008. Global diversity of water mites (Acari, Hydrachnidia; Arachnida) in freshwater. Hydrobiologia 595, 303-315.

Douady, C.J., Delsuc, F., Boucher, Y., Doolittle, W.F., Douzery E.J.P., 2003. Comparison of Bayesian and maximum likelihood bootstrap measures of phylogenetic reliability. Mol. 
Biol. Evol. 20, 248-254.

Drummond, A.J., Ho, S.Y.W., Phillips, M.J., Rambaut A., 2006. Relaxed phylogenetics and dating with confidence. PLOS Biology 4, 0699-0710.

Drummond, A.J., Suchard, M.A., Xie, D., Rambaut, A. 2012. Bayesian phylogenetics with BEAUti and the BEAST 1.7. Mol. Biol. Evol. 29, 1969-1973.

Dubinin, V.B., 1962. Class Acaromorpha: mites or gnathosomic chelicerate arthropods, in: Rodendorf, B.B. (Ed.), Fundamentals of palaeontology. Academy of Sciences of the USSR, Moscow, pp 447-473. [In Russian]

Dunlop, J.A., 2007. A large parasitengonid mite (Acari, Erythraeoidea) from the early Cretaceous Crato Formation of Brazil. Foss. Rec. 10:91-98.

Dunlop, J.A., Bertrand, M., 2011. Fossil labidostomatid mites (Prostigmata: Labidostommatidae) from Baltic amber. Acarologia 51:191-198.

Ewing, H.E., 1937. Acarina from Canadian amber. Uni. Tor. Stud. Geol. Ser. 40, 56-62.

Felsenstein, J., 1985. Confidence limits on phylogenies: An approach using the bootstrap. Evolution 39, 783-791.

Frisch, W. Meschede, M., Blakey, R.C. 2011. Plate Tectonics: Continental Drift and Mountain Building. Springer-Verlag, Berlin.

Gernhard, T., 2008. The conditioned reconstructed process. J. Theor. Biol. 253, 769-78.

Goldman, N., Yang, Z., 1994. A codon-based model of nucleotide substitution for protein-coding DNA sequences. Mol. Biol. Evol. 11, 725-36.

Harvey, M.S., 1998. The Australian water mites: a guide to families and genera. Monographs on Invertebrate Taxonomy, Vol. 4. CSIRO Publishing: Collingwood, Victoria.

Hirst, S., 1923. On some arachnid remains from the Old Red Sandstone (Rhynie Chert Bed, Aberdeenshire). Ann. Mag. Nat. Hist. 12, 455-474.

Holland, B., Moulton, V., 2003. Consensus networks: a method for visualising incompatibilities in collections of trees, in: Benson, G., Page, R. (Eds.), Algorithms in bioinformatics. WABI 2003. Springer-Verlag, Berlin, Germany, pp. 165-176.

Huson, D.H., Bryant, D., 2006. Application of phylogenetic networks in evolutionary studies. 
Mol. Biol. Evol. 23, 254-267.

Jin, D.-C., 2000. Cladistics and phylogeny of superfamily relationships within Hydrachnellae (Acari, Acariformes). Acta Entomologica Sinica 43: 309-317.

Judson, M., Mąkol, J., 2009. A mite of the family Tanaupodidae (Arachnida, Acari, Parasitengona) from the Lower Cretaceous of France. Geodiversitas 31, 41-47.

Judson, M., Wunderlich, J., 2003. Rhagidiidae (Acari, Eupodoidea) from Baltic amber. Acta Zool. Cracov. 46 [Suppl.-Fossil Insects], 147-152.

Kennedy, M., Holland, B.R., Gray, R.D., Spencer H.G., 2005. Untangling long branches: Identifying conflicting phylogenetic signals using Spectral Analysis, Neighbor-Net, and Consensus Networks. Syst. Biol. 54, 620-633.

Kerfoot, W.C., 1982. A question of taste: crypsis and warning coloration in freshwater zooplankton communities. Ecology 63, 538-554.

Kethley, J., 1991. Calyptostasic nymphs of Neonanorchestes (Nanorchestidae): a third example of alternating calyptostasy, in: Dusbabek, F., Bukva, V. (Eds.), Modern Acarology. Academia, Prague, vol. 2, pp. 279-282.

Kethley, J. B., 1982. Prostigmata, in: Parker, S.P. (Ed.), Synopsis and Classification of Living Organisms. New York: McGraw-Hill, pp. 117-145.

Koch, C.L., Berendt, G.C., 1854. Die im Bernstein befindlichen Myriapoden, Arachniden und Apteren der Vorwelt, in: Berendt, G.C. (Ed.), Die in Bernstein Befindlichen Organischen Reste der Vorwelt Gesammelt in Verbindung mit Mehreren Bearbeitetet und Herausgegeben 1. Nicolai, Berlin.

Krantz, G.W., 2009. Form and function, in: Krantz, G.W., Walter, D.E. (Eds.), A Manual of Acarology, 3rd Edition. Texas Tech University Press, Lubbock, pp. 5-53.

Krantz, G.W., Walter D.E., 2009. A Manual of Acarology, 3rd Edition. Texas Tech University Press, Lubbock.

Kulicka, R., 1990. The list of animal inclusions in Baltic amber from collection of the museum of earth in Warsaw. Prace Muzeum Ziemi 41, 144-146.

Lang, P., 1905. Über den Bau der Hydrachnidenaugen. Zoologische Jahrbücher Anatomie 21:453-494.

Maddison, D.R., Maddison, W.P., 2005. MacClade 4: Analysis of phylogeny and character 
evolution. Version 4.0, Sunderland, Massachusetts, Sinauer Associates.

Maddison, W.P., Maddison, D.R., 2014. Mesquite: a modular system for evolutionary analysis. Version $3.0 \mathrm{http}: / /$ mesquiteproject.org.

Mąkol, J., Wohltmann, A., 2012. An annotated checklist of terrestrial Parasitengona (Actinotrichida: Prostigmata) of the world, excluding Trombiculidae and Walchiidae. Ann. Zool. 62, 359-562.

Mar, J.C., Harlow, T.J., Ragan, M.A., 2005. Bayesian and maximum likelihood phylogenetic analyses of protein sequence data under relative branch-length differences and model violation. BMC Evol. Biol. 5, 8.

Merl, D., Escalante, A., Prado, R., 2005. Comparison of Bayesian, maximum likelihood and parsimony methods for detecting positive selection. AMS Tech. Report 3, 37.

Müller, K. F., 2004. PRAP - computation of Bremer support for large data sets. Mol. Phylogenet. Evol. 31, 780-782.

Newell, I.M., 1957. Studies on the Johnstonianidae (Acari, Parasitengona). Pacific Science 11: 396-466.

Nicholas, K.B., Nicholas, H.B. Jr., 1997. GeneDoc: a tool for editing and annotating multiple sequence alignments. Pittsburgh Supercomputing Center's National Resource for Biomedical Supercomputing. Available from http://www.nrbsc.org/downloads/ (accessed 2 March 2007, ver. 2.7.000).

Page, R.D.M., 1996. TREEVIEW: An application to display phylogenetic trees on personal computers. Comput. Appl. Biosci. 12, 357-358.

Pepato, A.R., Klimov, P.B., 2015. Origin and higher-level diversification of acariform mites evidence from nuclear ribosomal genes, extensive taxon sampling, and secondary structure alignment. BMC Evol. Biol. 15:178.

Pepato, R., da Rocha, C.E.F., Dunlop, J., 2010. Phylogenetic position of the acariform mites: sensitivity to homology assessment under total evidence. BMC Evol. Biol. 10, 235.

Petrunkevitch, A.I., 1913. A monograph of the terrestrial Palaeozoic Arachnida of North America. Trans. Conn. Acad. Arts Sci. 18, 1-137.

Phillips, M.J., 2009. Branch-length estimation bias misleads molecular dating for a vertebrate mitochondrial phylogeny. Gene 441132-140. 
Pickett, K.M., Tolman, G.L., Wheeler, W.C., Wenzel, J.W., 2005. Parsimony overcomes statistical inconsistency with the addition of more data from the same gene. Cladistics 21 , 438-445.

Poinar, G.O. Jr., 1985. Fossil evidence of insect parasitism by mites. Int. J. Acarol. 11, 37-38.

Posada, D., 2008. jModelTest: Phylogenetic Model Averaging. Mol. Biol. Evol. 25, 1253-1256.

Proctor, H.C., 1991. The evolution of copulation in water mites: a comparative test for nonreversing characters. Evolution 45, 558-567.

Proctor, H.C., Garga, N., 2004. Red, distasteful water mites: did fish make them that way? Exp. Appl. Acarol. 34, 127-147.

Proctor, H.C., Pritchard, G., 1989. Neglected predators: water mites (Acari: Parasitengona: Hydrachnellae) in freshwater communities. J. N. Am. Benthol. Soc. 8, 100-111.

Proctor, H.C., Smith, I.M., Cook, D.R., Smith, B.P., 2015. Subphylum Chelicerata Class Arachnida, in: Thorp, J.H., Rogers, D.C. (Eds.), Thorp and Covich's Freshwater Invertebrates, $4^{\text {th }}$ Edition, Volume 1: Ecology and General Biology. Academic Press, Elsevier Inc., London, pp. 600-660.

Pyron, R.A., Burbrink, F.T., Colli, G.R., de Oca, A.N., Vitt, L.J., Kuczynski, C.A., Wiens J.J., 2011. The phylogeny of advanced snakes (Colubroidea), with discovery of a new subfamily and comparison of support methods for likelihood trees. Mol. Phylogenet. Evol. 58, 329-342.

Rambaut, A., 2014. FigTree v. 1.4.2. http://tree.bio.ed.ac.uk/software/figtree/.

Rambaut A., Drummond, A.J., 2007. Tracer v1.4, Available from http://beast.bio.ed.ac.uk/Tracer.

Reeb, V., Lutzoni, F., Roux, C., 2004. Contribution of RPB2 to multilocus phylogenetic studies of the euascomycetes (Pezizomycotina, Fungi) with special emphasis on the lichenforming Acarosporaceae and evolution of polyspory. Mol. Phylogenet. Evol. 32, 10361060.

Robinson-Rechavi, M., Huchon, D., 2000. RRTree: Relative-rate tests between groups of sequences on a phylogenetic tree. Bioinformatics 16, 296-297.

Ronquist, F., Teslenko, M., van der Mark, P., Ayres, D.L., Darling, A., Höhna, S., Larget, B., Liu, L., Suchard, M.A., Huelsenbeck, J.P., 2012. MrBayes 3.2: efficient Bayesian phylogenetic inference and model choice across a large model space. Syst. Biol. 61, 539- 
542.

Schwoerbel, J. 1986. Acari: Limnholacaridae und Hydrovolziidae, in: Stygofauna Mundi, Botosaneanu, L. (Ed.), E.J. Brill - Dr. W. Backhuys, Leiden, pp. 643-647.

Shimodaira, H., Hasegawa, M., 1999. Multiple comparisons of log-likelihoods with applications to phylogenetic inference. Mol. Biol. Evol. 16, 1114-1116.

Smith, I.M., 1976. A study of the systematics of the water mite family Pionidae (Prostigmata: Parasitengona). Memoirs of the Entomological Society of Canada 98, 1-249.

Smith, I.M., 1982. Larvae of water mites of the genera of the superfamily Lebertioidea (Prostigmata: Parasitengona) in North America with comments on phylogeny and higher classification of the superfamily. The Canadian Entomologist 114, 901-990.

Smith, I.M., Cook, D.R., Smith, B.P., 2010. Water mites (Hydrachnidiae) and other arachnids, in: Thorp, J.H., Covich, A.P. (Eds.), Ecology and Classification of North American Freshwater Invertebrates, 3rd ed. Academic Press, pp. 485-586.

Smith, I.M., Oliver, D.R., 1986. Review of parasitic associations of larval water mites (Acari: Parasitengona: Hydrachnida) with insect hosts. Can. Entomol. 118, 407-472.

Söller, R., Wohltmann, A., Witte, H., Blohm, D., 2001. Phylogenetic relationships within terrestrial mites (Acari: Prostigmata, Parasitengona) inferred from comparative DNA sequence analysis of the mitochondrial cytochrome oxidase subunit I gene. Mol. Phylogenet. Evol. 18, 47-53.

Stamatakis A., 2006. RAxML-VI-HPC: Maximum Likelihood-based Phylogenetic Analyses with Thousands of Taxa and Mixed Models. Bioinformatics 22(21), 2688-2690.

Swofford D.L., 2002. PAUP*. Phylogenetic Analysis Using Parsimony (*and Other Methods). Version 4. Sinauer Associates, Sunderland, Massachusetts.

Tamura K., Stecher G., Peterson D., Filipski A., Kumar S., 2013. MEGA6: Molecular Evolutionary Genetics Analysis version 6.0. Mol. Biol. Evol. 30, 2725-2729.

Thompson, J.D., Gibson, T.J., Plewniak, F., Jeanmougin, F., Higgins D.G., 1997. The ClustalX windows interface: flexible strategies for multiple sequence alignment aided by quality analysis tools. Nucleic Acids Res. 24, 4876-4882. 
Thorp, J.H., Rogers, D.C., 2015. Thorp and Covich's Freshwater Invertebrates, 4rth Ed., Volume 1: Ecology and General Biology. Academic Press, Elsevier Inc., London.

Varma, M.G.R., 1993. Ticks and mites, in: Land, R.P., Crosskey, R.W., (Eds). Medical Insects and Arachnids. Chapman \& Hall, London, pp. 597-658.

Walter, D.E., Lindquist, E.E., Smith, I.M., Cook, D.R., Krantz, G.W., 2009. Order

Trombidiformes, in: Krantz, G.W., Walter, D.E., (Eds.), A Manual of Acarology, 3rd Edition. Texas Tech University Press, Lubbock, pp. 233-420.

Welbourn, W.C., 1991. Phylogenetic studies of the terrestrial Parasitengona, in: Dusbábek, F., Bukva,V. (Eds.), Modern Acarology, vol. 2. The Hague: SPB Academic Publishing bv; Prague: Academia, pp. 163-170.

Wiens, J.J., Kuczynski, C.A., Smith, S.A., Mulcahy, D.G., Sites, J.W., Townsend, T.M., Reeder, T.W., 2008. Branch lengths, support, and congruence: Testing the phylogenomic approach with 20 nuclear loci in snakes. Syst. Biol. 57, 420-431.

Witte, H., 1991a. Indirect sperm transfer in prostigmatic mites from a phylogenetic viewpoint, in: Schuster, R., Murphy, P.W., (Eds.), The Acari: Reproduction, development and life-history strategies. Chapman \& Hall: London, pp. 137-176.

Witte, H., 1991b. The phylogenetic relationships within the Parasitengonae. In: Dusbábek, F., Bukva,V. (Eds.), Modern Acarology, vol. 2. The Hague: SPB Academic Publishing bv; Prague: Academia; pp. 171-82.

Witte, H., Döring, D., 1999. Canalized pathways of change and constraintes in the evolution of reproductive modes of microarthropods. Exp. Appl. Acarol. 23, 181-216.

Witte, H., Olomski, R., 1999. The evolutionary transformation of functional systems in the Parasitengona, in: Needham, G.R., Mitchell, R., Horn, D.J., Welbourn, W.C., (Eds.), Acarology IX Volume 2 Symposia, The Ohio Biological Survey, Columbus, Ohio, USA, pp. $125-137$.

Wohltmann, A., 2000. The evolution of life histories in Parasitengona. Acarologia 41, 145-204. Wohltmann, A., Makol, J., Gabryś, G., 2004. A revision of European Johnstonianinae (Acari: Prostigmata: Parasitengona: Trombidioidea). Annales Zoologici (Warszawa) 54: 595-630. Yeates, D.K., 1996. Groundplans and exemplars: paths to the tree of life. Cladistics 11, 343-357. 
Yeates, D.K., Wiegmann, B.M., Courtney, G.W., Meier, R., Lambkin, C., Pape, T., 2007. Phylogeny and systematics of Diptera: Two decades of progress and prospects. Zootaxa, $1668,565-590$.

Zacharda, M., Krivoluckij, D.A., 1985. Prostigmatic mites (Acarina: Prostigmata) from the Upper Cretaceous and Paleogene amber of the USSR. Vest. Cesk. Ven. Spol. Zool. 49, 147-152.

Zawal, A., 2008. Morphological characteristics of water mite larvae of the genus Arrenurus Duges, 1834, with notes on the phylogeny of the genus and an identification key. Zootaxa 1765: 1-75.

Zhang, Z.-Q., Fan, Q.-H., Pesic, V., Smit, H., Bochkov, A.V., Khaustov, A.A., Baker, A., Wohltmann, A., Wen, T.-H., Amrine, J.W., Beron, P., Lin, J.-Z., Gabrys, G., Husband, R., 2011. Order Trombidiformes Reuter, 1909, in: Zhang, Z-Q., (Ed.) Animal biodiversity: an outline of higher-level classification and survey of taxonomic richness. Zootaxa, 3148: $129-138$.

Zwickl, D.J., 2006. Genetic algorithm approaches for the phylogenetic analysis of large biological sequence data sets under the maximum likelihood criterion. Ph.D. Thesis. The University of Texas, Austin. 
Figure captions

Fig. 1 Maximum Likelihood tree (topologically consistent with Bayesian Inference tree) calculated for combined $18 \mathrm{~S}+28 \mathrm{~S}+\mathrm{COI}$ dataset. Values near branches show Bayesian posterior probability (PP) and bootstrap support (BS), respectively. Nodes with support values below cutoff value $(0.5 / 50 \%)$ are collapsed into polytomies. Symbols used: * perfect support $(\mathrm{PP}=1$, $\mathrm{BS}=100 \%),-$ no support $(\mathrm{PP}<0.5, \mathrm{BS}<50 \%)$. Para- or polyphyletic taxa are in quotation marks.

Fig. 2 Phylogenetic conflict in the $18 \mathrm{~S}, 28 \mathrm{~S}$, and combined $18 \mathrm{~S}+28 \mathrm{~S}+\mathrm{COI}$ BI trees of Parasitengonina superfamilies revealed by Consensus Network analysis conducted on last 2500 Bayesian trees from burn-out fraction. Numbers at splits are confidence values for alternative hypotheses. Threshold for all analyses set to 0.33 . There are no conflicts between superfamilies in the combined analysis of $18 \mathrm{~S}+28 \mathrm{~S}+\mathrm{COI}$ dataset, even after lowering the threshold to 0.25 .

Fig. 3 Origin and divergence time of water mites and their trombidiform outgroups. Chronogram estimated using BEAST analysis with constrained tree corresponding to Fig. 1. Numbers in circles represent fossil calibration points (see Tab. 2). The chronostratigraphic scale is given with absolute geological ages (MYA, million years ago). Yellow bars indicate credibility intervals (+95\% highest posterior densities HPD). Dating of the origin of Diptera after Bertone et al. (2008).

Fig. 4 Character tracing of selected discrete morphological and ecological characters of Parasitengonina. Changes were traced onto the final tree (Fig. 1) using likelihood Markov k-state 1 parameter model for reconstruction of ancestral states in Mesquite. If the reversals were not justified biologically, asymmetrical 2-parameter Markov model with differently set forward/backward rates of character state changes was also applied. A - G - characters \#1 to \#7 used in the analysis (see Tab. S2). 
Table 1. List of taxa and sequences used in the phylogenetic analyses. Sequences with accession numbers KM100874-KM101029 (155) were generated in this study.

Table 2. Fossils used as calibration points for divergence time estimation. MAC - minimum age constraint (in millions of years ago). Node numbers as in the chronogram shown in Fig. 3. 


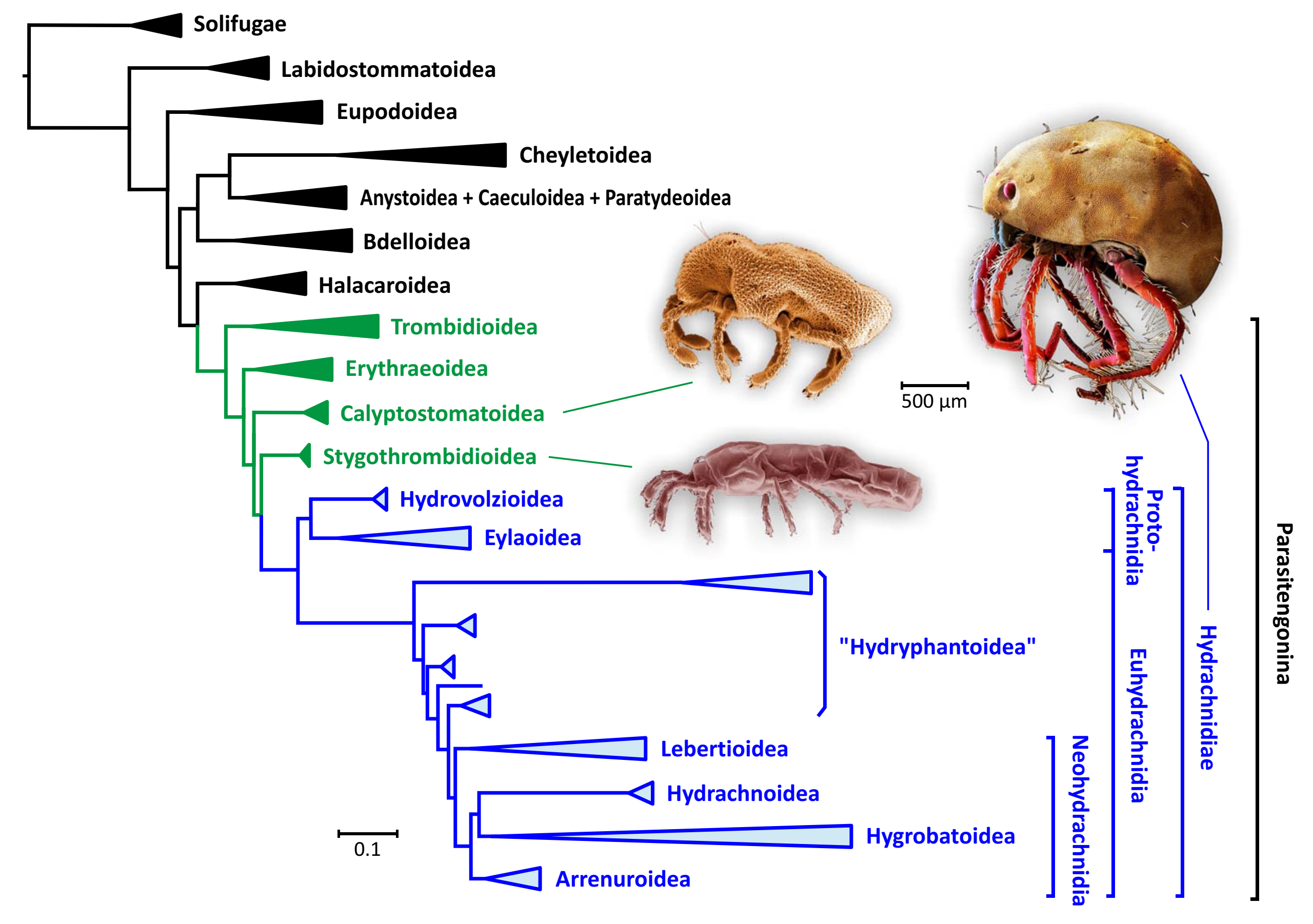


Eusimonia wunderlichi $\sqsupset$ Karschiidae

* ${ }_{*}$ Chanbria regalis Eremobates sp.

- Gluvia dorsalis $\sqsupset$ Daesiidae

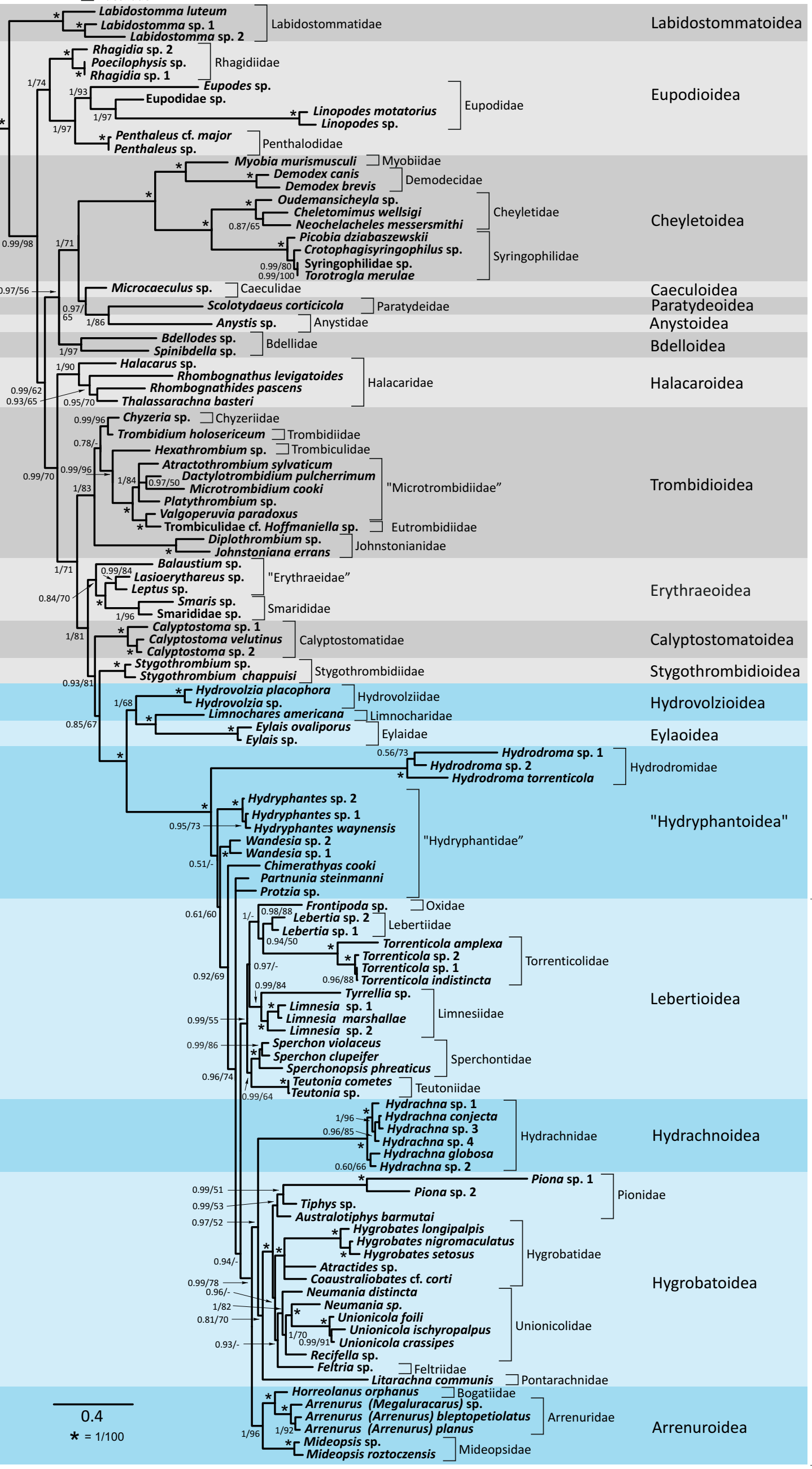


$18 S$


Hygrobatoidea

Stygothrombidioidea


Stygothrombidioidea basal to Calyptostomatoidea
Trombidioidea basal to Calyptostomatoidea
Arrenuroidea are paraphyletic






\section{Origin of Diptera}

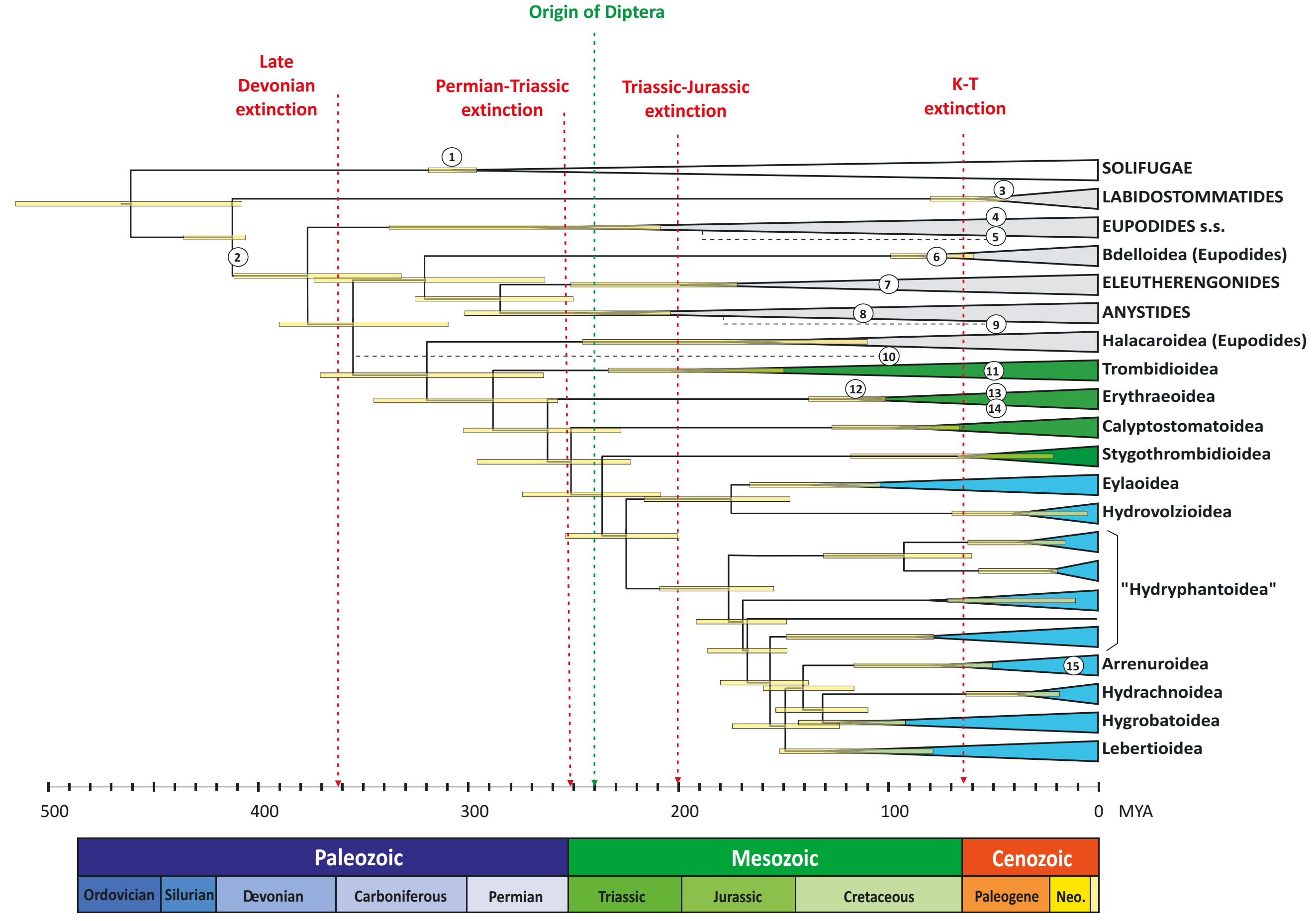



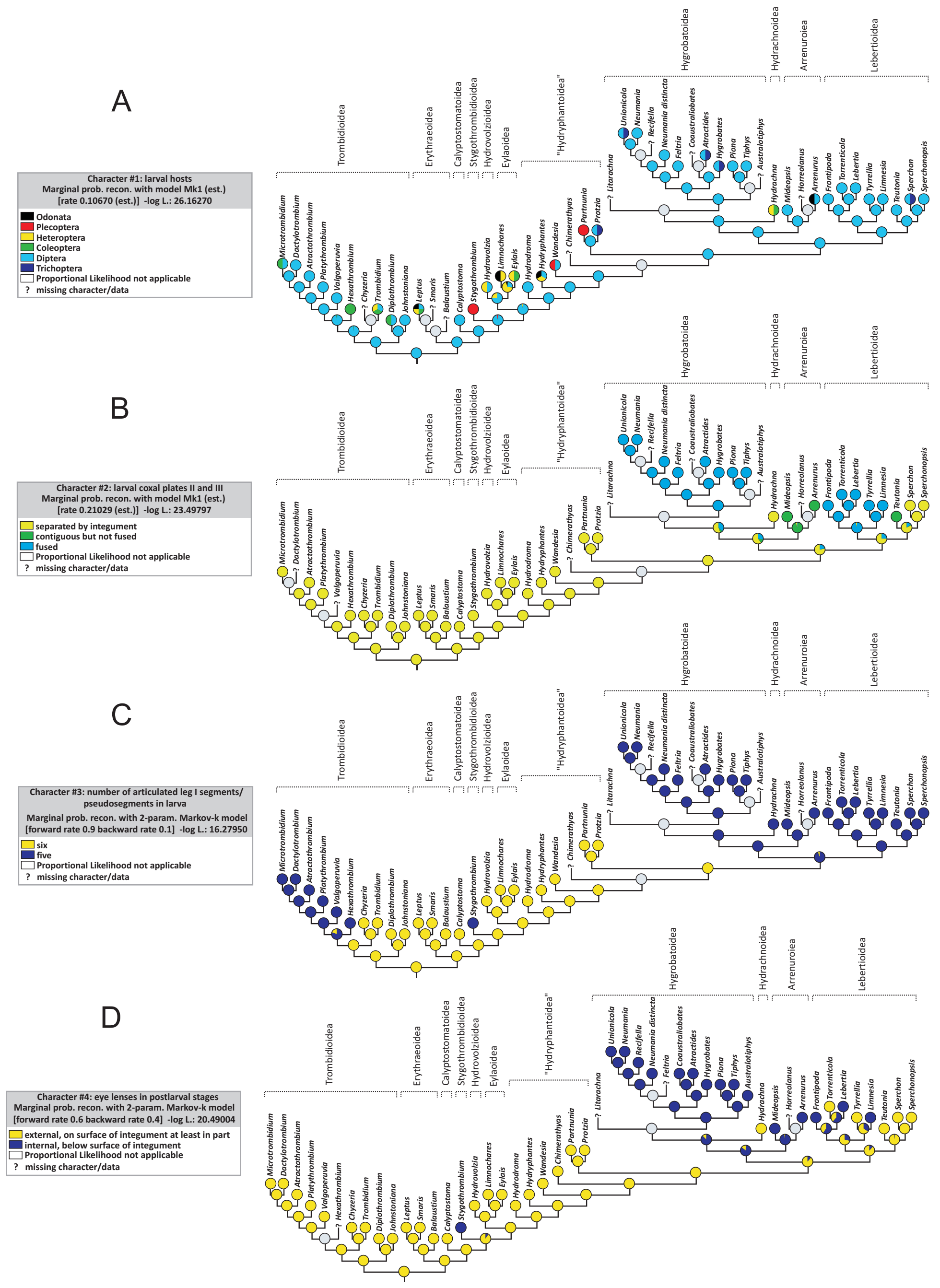

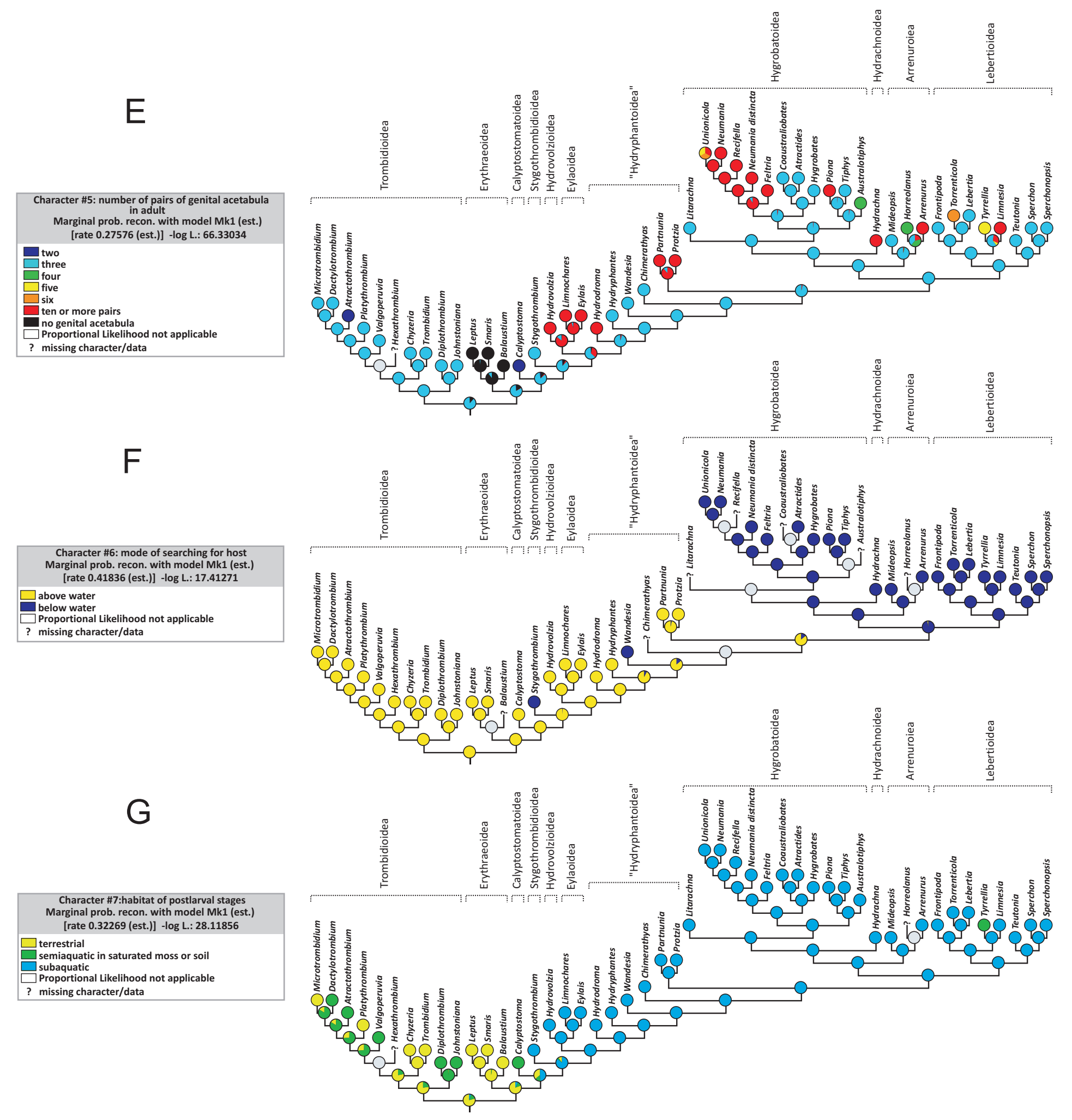

Character \#6: mode of searching for host [rate 0.41836 (est.)] -log L.: 17.41271

above water ? missing character/data

G

Character \#7:habitat of postlarval stages Marginal prob. recon. with model Mk1 (est.) [rate 0.32269 (est.)] - $\log$ L.: 28.11856 ? missing character/data below water
F$$
\text { (1) }
$$

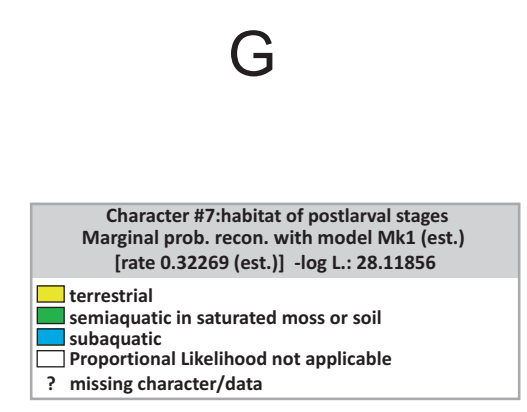


Table 1

\begin{tabular}{|c|c|c|c|c|c|}
\hline HIGHER TAXONOMIC RANK & FAMILY & SPECIES & 18S RRNA & 28S RRNA & COI \\
\hline \multirow[t]{4}{*}{ SOLIFUGAE } & Daesiidae & Gluvia dorsalis & AF007103 & KM100936 & KM100979 \\
\hline & Eremobatidae & Chanbria regalis & AF124931 & AF062983 & - \\
\hline & & Eremobates sp. & AY859573 & AY859572 & - \\
\hline & Karschiidae & Eusimonia wunderlichi & U29492 & AF124958 & - \\
\hline ACARIFORMES: & Cheyletidae & Cheletomimus wellsigi & HM070363 & - & - \\
\hline TROMBIDIFORMES & & Cheyletus carnifex & - & - & HQ404359 \\
\hline ELEUTHERENGONIDES & & Neochelacheles messersmithi & AY620908 & - & - \\
\hline \multirow[t]{8}{*}{ COHORT RAPHIGNATHINA } & & Oudemansicheyla sp. & HM070362 & - & - \\
\hline & Demodicidae & Demodex brevis & GU377178 & - & - \\
\hline & & D. canis & HQ727998 & - & - \\
\hline & Syringophilidae & Crotophagisyringophilus sp. & KM100881 & - & - \\
\hline & & Picobia dziabaszewskii & KM100882 & - & JQ043358 \\
\hline & & Syringophilidae sp. & GQ864269 & - & - \\
\hline & & Torotrogla merulae & KM100883 & - & JN160609 \\
\hline & Myobiidae & Myobia murismusculi & JF834895 & - & - \\
\hline \multirow[t]{17}{*}{ EUPODIDES } & Bdellidae & Bdellidae sp.1 & - & - & KM100983 \\
\hline & & Bdellidae sp.2 & - & - & KM100984 \\
\hline & & Bdellodes sp. & HM070358 & - & - \\
\hline & & Spinibdella sp. & HM070368 & - & - \\
\hline & Eupodidae & Eupodes sp. & HM070365 & - & - \\
\hline & & Eupodidae sp. & GQ864273 & KM100954 & KM100982 \\
\hline & & Linopodes motatorius & GQ864270 & - & - \\
\hline & & Linopodes sp. & GQ864274 & - & - \\
\hline & Penthaleidae & Penthaleus cf. major & GQ864271 & - & GQ864389 \\
\hline & & Penthaleus sp. & - & KM100952 & GQ864391 \\
\hline & Rhagidiidae & Poecilophysis sp. & HM070360 & $\begin{array}{c}\mathrm{HM} 07032 \\
3\end{array}$ & - \\
\hline & & Rhagidia sp.1 & GQ864275 & - & KM100981 \\
\hline & & Rhagidia sp.2 & GQ864272 & KM100953 & KM100980 \\
\hline & Halacaridae & Halacarus sp. & HM070350 & - & - \\
\hline & & Rhombognathides pascens & AY692341 & - & - \\
\hline & & Rhombognathus levigatoides & HM070351 & - & - \\
\hline & & Thalassarachna basteri & AY692342 & - & - \\
\hline \multirow[t]{3}{*}{ LABIDOSTOMMATIDES } & Labidostommatidae & Labidostomma luteum & GQ864278 & KM100974 & GQ864390 \\
\hline & & Labidostomma sp. 1 & EF203774 & - & - \\
\hline & & Labidostomma sp. 2 & AF022034 & - & - \\
\hline ANYSTIDES & Anystidae & Anystis sp. & AF022026 & - & - \\
\hline \multirow[t]{2}{*}{ COHORT ANYSTINA } & Caeculidae & Microcaeculus sp. & AF287232 & - & - \\
\hline & Paratydeidae & Scolotydaeus corticicola & HM070367 & - & - \\
\hline COHORT PARASITENGONINA & Calyptostomatidae & Calyptostoma sp. 1 & KM100878 & KM100948 & KM100992 \\
\hline \multirow[t]{7}{*}{ SUBCOHORT ERYTHRAIAE } & & Calyptostoma sp. 2 & KM100879 & - & KM100994 \\
\hline & & C. velutinus & KM100880 & KM100949 & KM100993 \\
\hline & Erythraeidae & Balaustium sp. & EF203775 & - & - \\
\hline & & Lasioerythraeus sp. & KM100884 & KM100950 & KM100991 \\
\hline & & Leptus sp. & HM070355 & - & - \\
\hline & Smarididae & Smarididae sp. & HM070364 & - & - \\
\hline & & Smaris sp. & KM100885 & KM100951 & KM100990 \\
\hline \multirow[t]{11}{*}{ SUBCOHORT TROMBIDIAE } & Chyzeriidae & Chyzeria sp. & KM100929 & - & - \\
\hline & Trombiculidae & Trombiculidae cf. Hoffmaniella sp. & HM07035 & - & - \\
\hline & Eutrombidiidae & Hexathrombium sp. & KM100931 & - & - \\
\hline & Johnstonianidae & Diplothrombium sp. & KM100930 & KM100940 & KM100986 \\
\hline & & Johnstoniana errans & GQ864282 & KM100941 & - \\
\hline & Microtrombidiidae & Atractothrombium sy/vaticum & KM100928 & - & KM100989 \\
\hline & & Dactylothrombium pulcherrimum & GQ864281 & KM100939 & KM100985 \\
\hline & & Microtrombidium cooki & KM100935 & - & KM100987 \\
\hline & & Platythrombium sp. & KM100932 & KM100942 & - \\
\hline & & Valgoperuvia paradoxa & KM100934 & KM100943 & KM100988 \\
\hline & Trombidiidae & Trombidium holosericeum & KM100933 & - & - \\
\hline \multirow{3}{*}{$\begin{array}{c}\text { SUBCOHORT } \\
\text { STYGOTHROMBIAE }\end{array}$} & Stygothrombidiidae & Stygothrombium chappuisi & KM100926 & KM100937 & - \\
\hline & & & & & \\
\hline & & Stygothrombium sp. & KM100927 & KM100938 & KM100995 \\
\hline \multirow{8}{*}{$\begin{array}{l}\text { SUBCOHORT } \\
\text { HYDRACHNIDIAE }\end{array}$} & Arrenuridae & Arrenurus (Arrenurus) planus & KM100874 & - & - \\
\hline & & & & & \\
\hline & & A. (A.) bleptopetiolatus & - & - & KM101006 \\
\hline & & Arrenurus (A.) sp. & KM100875 & KM100944 & KM101003 \\
\hline & & Arrenurus (Megaluracarus) sp. & KM100876 & KM100945 & KM101005 \\
\hline & Bogatiidae & Horreolanus orphanus & AY620907 & KM100946 & KM101004 \\
\hline & Mideopsidae & Mideopsis roztoczensis & JN018219 & JN018316 & JN018102 \\
\hline & & Mideopsis sp. & KM100877 & KM100947 & KM101007 \\
\hline
\end{tabular}




\begin{tabular}{|c|c|c|c|c|}
\hline \multirow[t]{2}{*}{ Eylaidae } & Eylais ovaliporus & KM100886 & - & AB530317 \\
\hline & Eylais sp. & KM100887 & KM100955 & AY393896 \\
\hline Limnocharidae & Limnochares americana & KM100888 & KM100956 & KM100998 \\
\hline \multirow[t]{6}{*}{ Hydrachnidae } & Hydrachna conjecta & JN018220 & JN018317 & JN018103 \\
\hline & H. globosa & JN018221 & JN018318 & JN018104 \\
\hline & Hydrachna sp. 1 & HM070348 & $\begin{array}{c}\mathrm{HM} 07031 \\
1\end{array}$ & - \\
\hline & Hydrachna sp. 2 & KM100899 & - & - \\
\hline & Hydrachna sp. 3 & KM100900 & KM100961 & KM101008 \\
\hline & Hydrachna sp. 4 & KM100901 & - & - \\
\hline \multirow[t]{2}{*}{ Hydrovolziidae } & Hydrovolzia placophora & KM100889 & KM100957 & KM100996 \\
\hline & Hydrovolzia sp. & KM100890 & - & KM100997 \\
\hline \multirow[t]{3}{*}{ Hydrodromidae } & Hydrodroma sp. 1 & AF142112 & - & - \\
\hline & Hydrodroma sp. 2 & KM100892 & - & KM101009 \\
\hline & H. torrenticola & JN018222 & JN018319 & JN018105 \\
\hline \multirow[t]{8}{*}{ Hydryphantidae } & Chimerathyas cooki & KM100891 & KM100958 & - \\
\hline & Hydryphantes sp. 1 & KM100894 & - & KM101013 \\
\hline & Hydryphantes sp. 2 & KM100895 & - & KM101014 \\
\hline & H. waynensis & KM100893 & KM100959 & KM101012 \\
\hline & Partnunia steinmanni & GQ864276 & - & KM101016 \\
\hline & Protzia sp. & KM100896 & - & KM101015 \\
\hline & Wandesia sp. 1 & KM100897 & KM100960 & KM101010 \\
\hline & Wandesia sp. 2 & KM100898 & - & KM101011 \\
\hline Feltriidae & Feltria sp. & KM100905 & KM100965 & KM101021 \\
\hline \multirow[t]{6}{*}{ Hygrobatidae } & Atractides latisetus & - & - & EF633505 \\
\hline & Atractides sp. & KM100902 & KM100962 & - \\
\hline & Coaustraliobates cf. cortipes & KM100904 & KM100964 & KM101024 \\
\hline & Hygrobates nigromaculatus & KM100906 & KM100967 & FJ668542 \\
\hline & H. setosus & KM100907 & - & FJ668540 \\
\hline & Hygrobates sp. & GQ864277 & KM100966 & FJ668538 \\
\hline \multirow[t]{4}{*}{ Limnesiidae } & Limnesia (Limnesiella) marshallae & KM100910 & KM100969 & KM101029 \\
\hline & Limnesia sp. 1 & KM100909 & - & KM101027 \\
\hline & Limnesia sp. 2 & KM100908 & KM100968 & KM101028 \\
\hline & Tyrrellia sp. & KM100917 & - & KM101026 \\
\hline \multirow[t]{4}{*}{ Pionidae } & Australotiphys barmutai & KM100903 & KM100963 & KM101017 \\
\hline & Piona sp. 1 & KM100914 & - & KM101019 \\
\hline & Piona sp. 2 & KM100915 & - & KM101020 \\
\hline & Tiphys sp. & KM100916 & KM100972 & KM101018 \\
\hline Pontarachnidae & Litarachna communis & KM100911 & KM100970 & KM101025 \\
\hline \multirow[t]{6}{*}{ Unionicolidae } & Neumania distincta & KM100912 & - & - \\
\hline & Neumania sp. & KM100913 & KM100971 & KM101022 \\
\hline & Recifella sp. & HM070347 & - & - \\
\hline & Unionicola crassipes & KM100918 & KM100973 & KM101023 \\
\hline & U. foili & JN018306 & JN018403 & NC_01103 \\
\hline & U. ischyropalpus & - & - & FJ218017 \\
\hline \multirow[t]{2}{*}{ Lebertiidae } & Lebertia sp. 1 & KM100920 & - & KM101001 \\
\hline & Lebertia sp. 2 & - & - & AY393897 \\
\hline Oxidae & Frontipoda sp. & KM100919 & KM100975 & KM101000 \\
\hline \multirow[t]{4}{*}{ Sperchontidae } & Sperchon clupeifer & KM100921 & KM100976 & - \\
\hline & Sperchon sp. & - & - & AB530314 \\
\hline & S. violaceus & GQ864279 & KM100977 & GQ864400 \\
\hline & Sperchonopsis phreaticus & KM100922 & KM100978 & KM100999 \\
\hline \multirow[t]{2}{*}{ Teutoniidae } & Teutonia cometes & JN018224 & JN018321 & JN018107 \\
\hline & Teutonia sp. & JN018225 & JN018322 & JN018108 \\
\hline \multirow[t]{4}{*}{ Torrenticolidae } & Torrenticola amplexa & JN018226 & JN018323 & JN018191 \\
\hline & T. indistincta & KM100923 & - & - \\
\hline & Torrenticola sp. 1 & KM100924 & - & - \\
\hline & Torrenticola sp. 2 & KM100925 & - & KM101002 \\
\hline
\end{tabular}




\begin{tabular}{|c|c|c|c|c|}
\hline Taxonomy & Oldest fossil record & MYC & Reference & Node \# \\
\hline Solifugae & Carboniferous, Upper & 308 & Petrunkevitch (1913) & 1 \\
\hline \multicolumn{5}{|l|}{ Endeostigmata } \\
\hline $\begin{array}{l}\text { Alicorhagiidae, } \\
\text { Alycidae }^{\mathrm{a}}\end{array}$ & Devonian, Pragian & 410 & Hirst (1923), Dubinin (1962) & 2 \\
\hline \multicolumn{5}{|l|}{ Trombidiformes } \\
\hline Labidostommatidae & Paleogene, Eocene & 45 & Dunlop and Bertrand (2011) & 3 \\
\hline Penthalodidae & Paleogene, Eocene & 49 & Koch and Berendt (1854) & 4 \\
\hline Rhagidiidae & Paleogene, Eocene & 49 & Judson and Wunderlich (2003) & 5 \\
\hline Bdellidae & Cretaceous, Campanian & 78 & Ewing (1937) & 6 \\
\hline Cheyletidae & Cretaceous, Albian & 100 & Cockerell (1917) & 7 \\
\hline Anystidae & Cretaceous, Albian & 112 & Zacharda and Krivoluckij (1985) & 8 \\
\hline Caeculidae & Paleogene, Eocene & 49 & Coineau and Magowski (1994) & 9 \\
\hline Tanaupodidae ${ }^{\mathrm{b}}$ & Cretaceous, Albian & 100 & Judson and Mąkol (2009) & 10 \\
\hline Trombidiidae & Paleogene, Eocene & 50 & Koch and Berendt (1854) & 11 \\
\hline Erythraeoidea & Cretaceous, Albian & 115 & Dunlop (2007) & 12 \\
\hline Erythraeidae & Paleogene, Oligocene & 49 & Koch and Berendt (1854) & 13 \\
\hline Smarididae & Paleogene, Oligocene & 49 & Kulicka (1990) & 14 \\
\hline Arrenuroidea $^{c}$ & Miocene, Neogene & 12 & Cook in Palmer (1957) & 15 \\
\hline \multicolumn{5}{|c|}{$\begin{array}{l}\text { a It is the earliest fossil record of Acariformes; we used it as calibration point of basal node of Prostigmata since } \\
\text { this group is a basal acariform lineage (Dabert et al., 2010). } \\
{ }^{b} \text { Here used as calibration point of basal node of Parasitengonina. } \\
\text { c We have not applied the second known water mite fossil record from Paleogene, Oligocene ( } 35 \text { MYA) (Poinar, } \\
\text { 1985). These mites were ambiguously classified and could belong to one of the three superfamilies, } \\
\text { Hygrobatoidea, Arrenuroidea or Lebertiodea. Therefore this record could not be used as a calibration point for } \\
\text { a specific clade. }\end{array}$} \\
\hline
\end{tabular}

